\title{
Investigating students' mental models about the quantization of light, energy, and angular momentum
}

\author{
Nilüfer Didiş \\ Department of Elementary Education, Bülent Ecevit University, 67300 Zonguldak, Turkey \\ Ali Eryılmaz \\ Department of Secondary Science and Mathematics Education, \\ Middle East Technical University, 06800 Ankara, Turkey \\ Şakir Erkoç \\ Department of Physics, Middle East Technical University, 06800 Ankara, Turkey
}

(Received 8 January 2014; published 18 November 2014)

\begin{abstract}
This paper is the first part of a multiphase study examining students' mental models about the quantization of physical observables - light, energy, and angular momentum. Thirty-one second-year physics and physics education college students who were taking a modern physics course participated in the study. The qualitative analysis of data revealed six variations in students' mental models about the quantization of physical observables: scientific model, primitive scientific model, shredding model, alternating model, integrative model, and evolution model. These models were determined to be context dependent. In addition, some students are in a mixed-model state where they use multiple mental models in explaining a phenomenon and use these models inconsistently.
\end{abstract}

DOI: 10.1103/PhysRevSTPER.10.020127

PACS numbers: 01.40.Fk

\section{INTRODUCTION}

\section{A. Mental models}

One of the theories about knowledge organization is "mental modeling." A mental model, briefly, is "an internal representation which acts out as a structural analogue of situations or processes. Its role is to account for the individuals' reasoning both when they try to understand discourse and when they try to explain and predict the physical world behavior" [1]. Craik [2] is accepted as the pioneer of the theory of mental models. In his book titled, "The Nature of Explanation," he stated that human thought has the power to predict events (p. 50) and provided smallscale models to explain processes (p. 59). After forty years, the mental model term was used in two different books with the same name, Johnson-Laird's [3] and Gentner and Stevens's [4] "Mental Models." While Johnson-Laird's (1983) book explained the theory from the perspective of psychology, Gentner and Stevens's [4] book clarified it from the perspective of "science education" by editing different researchers' studies and identifying students' mental models of science concepts.

Published by the American Physical Society under the terms of the Creative Commons Attribution 3.0 License. Further distribution of this work must maintain attribution to the author(s) and the published article's title, journal citation, and DOI.
Johnson-Laird ([3], p. 10) expressed that understanding occurs with working models in the mind, and to understand a scientific theory requires the construction of mental models. Therefore, learning occurs during the active construction of mental models. When the material students learn is consistent with existing mental models, these models facilitate their learning [5,6]. Norman [7] stated several identifying characteristics of mental models:

- "Mental models are incomplete.

- People's abilities to 'run' their models are severely limited.

- Mental models are unstable: People forget the details of the system they are using, especially when those details have not been used for some period.

- Mental models do not have firm boundaries: similar devices and operations get confused with one another.

- Mental models are 'unscientific': People maintain 'superstitious' behavior patterns even when they know they are unneeded because they cost little in physical effort and save mental effort.

- Mental models are parsimonious: Often people do extra physical operations rather than the mental planning that would allow them to avoid those actions; they are willing to trade-off extra physical action for reduced mental complexity. This is especially true where the extra actions allow one simplified rule to apply to a variety of devices, thus minimizing the chances for confusions." (p. 8). 
Gentner [5] elaborated on other characteristics of mental models:

- Reasoning coming out from mental models relies on qualitative relations (i.e., comparing two quantities without knowing the exact values).

- Mental models permit mental simulation (running a mental model and observing the outcome).

- People can hold two or more "inconsistent" mental models together in the same domain.

Redish [8] indicated another property of mental models as the following:

- "They consist of propositions, images, rules of procedure, and statements as to when and how they are to be used" (p. 797).

According to diSessa [9 cited in 10-12] mental models need to have certain characteristics. These are as follows:

- "Mental models should (1) involve a strong well developed 'substrate' knowledge system, such as spatial reasoning, (2) allow explicit hypothetical reasoning, and (3) involve only a small, well defined class of causal inferences" (pp. 53-54).

Therefore, we understand from the literature that mental models are very useful elements that people construct in their minds. The potential uses of mental modeling theory are wide ranging. Mental models have been examined by many different disciplines, and the ways in which researchers approach the topic of models differs. A mental model can be defined in several ways by stressing different properties. For example, the description of mental models from the perspective of physics educators is as follows:

- Bao [13] put forward his definition of mental models by considering other descriptions in the literature. According to him, mental models are "productive mental structures that can be applied to a variety of different physical contexts to generate explanatory results" (p. 13).

- Corpuz and Rebello [14] defined a mental model as "students' way of understanding a certain physical phenomenon," which can also be unseen physical phenomena [15].

- Bao and Redish [16] explained that a mental model is a knowledge element or a strongly associated set of knowledge elements with a robust and coherent characteristic.

- Hrepic, Zollman, and Rebello [12] explained their perception of a mental model as "A mental structure built of more fundamental cognitive and knowledge elements, e.g., p-prims or conceptual resources" (p. 1). In addition, the researchers stressed the "coherent" organization of these elements to form a mental model.

\section{B. Identification of students' mental models}

Studies of mental models can be classified into two groups, such as qualitative and quantitative investigations.
However, these are not mutually exclusive. While qualitative investigations focus on sequenced interviews through analysis of in-depth questions and responses over time across contexts [17], quantitative investigations focus on the development of tests used to identify mental models. So, a quantitative investigation may need "a qualitative examination" before developing a test to identify mental models. For this reason, quantitative studies are often used after or together with qualitative ones. The research on mental models in physics education is summarized in Table I.

Each type of examination makes different contributions. For example, while it is possible to see how students organize their knowledge over a period of time using qualitative investigations [10,12,14,15,19,23-25,27], a simultaneous examination of many students' mental models within a limited time span is possible with technology assisted quantitative investigations $[11,20,26]$. In addition, some of the designs use both approaches sequentially $[13,18,21]$. Each type of investigation needs carefully planned designs and there is no "unique" qualitative design for investigating mental models. Therefore, physics education researchers choose among several different designs that focus on particular issues, such as the examination of models

- in a course context (mainly at the university level),

- over a long period (such as one or two semesters),

- by following interviews with in depth questioning,

- in multiple contexts.

\section{Learning quantum physics and mental modeling}

Many students have difficulty in understanding the concepts of quantum theory because of its abstract nature and its requirement of complex mathematical formalism [28]. Also, instructors have difficulty while teaching quantum physics because it introduces a new philosophy that is different from classical physics, consists of abstract concepts, and lacks analogies and metaphors [29]. Pedagogical research on students' quantum physics learning conducted with a diverse range of data collection techniques and students in different countries showed that students had conceptual problems [29-43], mathematical problems [28,29,34-36,44-46], and visual problems $[32,47,48]$ while learning quantum physics. In addition, they have difficulty in discriminating classical and quantum concepts [13,28,30,31,38,39,44,46,49].

The identification of students' mental models about scientific phenomena is important for being able to understand their learning of scientific concepts. Table II summarizes the previous research and presents the need for this current study by reflecting previous research on mental models and quantum theory worldwide. In this table, the studies explained in the boxes are those most related to the research conducted in this study.

As seen in Table II, although there is a great amount of pedagogical research worldwide about quantum physics and mental models separately, there is limited research 
TABLE I. Summary of mental model research in physics in terms of model investigation approach.

\begin{tabular}{|c|c|c|c|}
\hline Research & Examined concepts & Research approach & Used techniques \\
\hline $\begin{array}{l}\text { Wittmann, Steinberg, } \\
\text { and Redish [18] }\end{array}$ & Mechanical waves & $\begin{array}{l}\text { First qualitative and } \\
\text { then quantitative }\end{array}$ & $\begin{array}{l}\text { Individual demonstration interviews, pretests } \\
\text { (short, ungraded quizzes that accompany tutorials), } \\
\text { examination questions, and specially designed } \\
\text { diagnostic tests }\end{array}$ \\
\hline $\begin{array}{l}\text { Borges and } \\
\quad \text { Gilbert [19] }\end{array}$ & Electricity & Qualitative & $\begin{array}{l}\text { Semi-structured interviews based on simple experiments } \\
\text { using a "predict-observe-explain" technique }\end{array}$ \\
\hline $\begin{array}{l}\text { Hrepic [10], } \\
\text { Hrepic, Zollman, } \\
\text { and Rebello [12] }\end{array}$ & Sound propagation & Qualitative & $\begin{array}{l}\text { Interviews before and after the instruction about } \\
\text { sound from different contexts }\end{array}$ \\
\hline $\begin{array}{l}\text { Hrepic [11], } \\
\text { Hrepic, Zollman, } \\
\text { and Rebello [20] }\end{array}$ & Sound propagation & $\begin{array}{l}\text { Quantitative based } \\
\text { on Hrepic }[10,11]\end{array}$ & $\begin{array}{l}\text { Conducting Linked Item Model Analysis (LIMA) on } \\
\text { Formative Assessment of Mental Models of Sound } \\
\text { Propagation (FAMM-Sound) }\end{array}$ \\
\hline Bao [13] & $\begin{array}{l}\text { Potential energy diagrams, } \\
\text { probability }\end{array}$ & $\begin{array}{l}\text { First qualitative and } \\
\text { then quantitative }\end{array}$ & $\begin{array}{l}\text { Tutorials, interviews, conceptual quizzes, homework } \\
\text { and exams, conducting "Model Analysis" technique } \\
\text { on the developed multiple-choice test }\end{array}$ \\
\hline $\begin{array}{l}\text { Itza-Ortiz, } \\
\text { Rebello, and } \\
\text { Zollman [21] }\end{array}$ & $\begin{array}{l}\text { Newton's second law in } \\
\text { mechanics and electricity }\end{array}$ & $\begin{array}{l}\text { First qualitative and } \\
\text { then quantitative }\end{array}$ & $\begin{array}{l}\text { A series of interviews in two semesters using some } \\
\text { FCI [22] questions, development of a multiple } \\
\text { choice test (with four-five options) with two } \\
\text { dimensions in mechanics and three dimensions } \\
\text { in electromagnetism }\end{array}$ \\
\hline $\begin{array}{l}\text { Corpuz [23], } \\
\text { Corpuz and } \\
\text { Rebello }[14,15]\end{array}$ & Microscopic friction & Qualitative & $\begin{array}{l}\text { Interviews in two sessions based on different } \\
\text { contexts using "Model eliciting activities" }\end{array}$ \\
\hline Scherr [24] & Special relativity & Qualitative & Interviews, tutorials \\
\hline Hubber [25] & Nature of light & Qualitative & Longitudinal study prior to, and following 12 th grade \\
\hline $\begin{array}{r}\text { Vadnere and } \\
\text { Joshi [26] }\end{array}$ & $\begin{array}{l}\text { Heat transfer, electromagnetic } \\
\text { radiation, blackbody } \\
\text { radiation, Wien law, etc. }\end{array}$ & Quantitative & $\begin{array}{l}\text { Conducting "Model analysis" technique on the } \\
\text { developed multiple-choice test }\end{array}$ \\
\hline $\begin{array}{l}\text { Chiou and } \\
\text { Anderson [27] }\end{array}$ & Heat conduction & Qualitative & Interviews \\
\hline
\end{tabular}

TABLE II. An overview of the main literature related to this study.

\begin{tabular}{|c|c|c|c|}
\hline & Quantization & Quantum physics & Other physics domains \\
\hline With mental modeling framework & & {$[13,26]$} & $\overline{[8,10-12,14-16,18,19,21,23-25,27],{ }^{a}}$ \\
\hline Without mental modeling framework & & {$[26,28-59],{ }^{\mathrm{a}}$} & Not of our interest. \\
\hline
\end{tabular}

${ }^{\mathrm{a}}$ Other research that could not be integrated into the table.

about quantum physics using a mental modeling framework. In addition, the first column of the table also shows that the "quantization" phenomenon has not been studied using a mental modeling framework anywhere before.

Investigation of mental models provides a theoretical framework for our investigation of students' understanding of physics concepts. In light of the existing literature, in this research we focused on students' understanding of some concepts of quantum theory using "mental models" as a theoretical framework. Then, our research questions were as follows:

- What are the second-year physics and physics education students' mental models of the quantization of physical observables (i.e., electromagnetic radiation or light, energy and angular momentum)?
- What are the characteristics (i.e., context dependency and purity) of second-year physics and physics education students' mental models of the quantization of physical observables?

Identification of mental models is not a simple process, since mental models can be complex. It is also difficult to distinguish fragmented elements and coherent structures by using a single question, but prior research offers indications that this can be done successfully through in-depth questioning and soliciting responses over time and across contexts [17]. With these aims, this study relied on several premises for examining students' mental models:

- We define a "mental model" as the knowledge structure that is composed of elements used coherently to explain a phenomenon. 
- We cannot see students' mental models directly in their minds. However, while investigating students' mental models, we make some inferences based on what they explained to us in the interviews as well as through tests, and in the classroom environment, etc.

- Mental models are coherent knowledge structures that allow explanation of physical phenomena and reasoning in qualitative physics problems.

- They include the organization of concepts related to the phenomena.

- Coherency, having a single conceptual framework, is required to specify a mental model.

- "They may not have firm boundaries and their elements might be confused with each other" ([7], p. 8).

- More than one model can be held together at the same time, and can be used inconsistently [5].

- They allow qualitative reasoning [5] about the explanation of experienced and hypothetical situations.

- They may exist as the organization of fragmented elements $[10,11,13,18,21,60]$. If the fragmented elements are not organized, i.e., if they are disconnected or incoherently used, an unorganized structure is called "no model"[10].

- As students develop their own mental models of the phenomena over a period of time, previously fragmented and memorized structures might be organized in situ. Then, students might later develop mental models of the phenomena by answering the questions immediately.

- Quantization is not an independent single concept, but it is the underlying idea of the paradigm shift between classical physics and quantum theory based on the interpretation of new experimental results. So, students' mental models about quantization of light, energy, and angular momentum in the photoelectric experiment, blackbody radiation and ultraviolet catastrophe, energy levels and atomic spectra, particle in a box, harmonic oscillator, the Bohr atom, and the quantum atom contexts can lend insight into students' understanding of quantum physics.

- Finally, since quantum physics does not allow "intuition," students' previous conceptions and linking of the new information with related concepts about the quantization phenomenon are important to their explanations of mental models about the quantization of physical observables.

With these considerations, this study follows previous mental model research $[8,10-16,18,21,23,24]$ in terms of the basic ideas about the framework of mental modeling. There are some methodological similarities, i.e., examination in more than one context and including a large number of students. However, this study differs from previous research on mental models in physics education in terms of research design, examined physics concepts, statement of data analysis with coding, intercoding, and constructing themes.

\section{METHODOLOGY}

\section{A. Description of the key issues in this research}

\section{Description of the modern physics course}

Quantum theory concepts are taught to physics and physics education students in three related compulsory courses: Modern Physics (PHYS 202), Quantum Physics (PHYS 300), and Quantum Mechanics (PHYS 431) in the physics department. The first course-Modern Physicsincludes two fundamental physics topics: relativistic physics and quantum physics. In this course, the "special theory of relativity, particle properties of waves, wave properties of particles, atomic structure, elementary quantum mechanics, many electron atoms, nuclear structure and radioactivity" [61] are introduced to students.

Modern Physics is a prerequisite course for the Quantum Physics and Quantum Mechanics courses. It is very important for students to make sense of the concepts taught in this course, because it introduces them to the primary ideas of quantum theory. This course constructs students' conceptual backgrounds about quantum theory. In addition, the class examines "the quantization of physical observables" in atomic systems. Students take Modern Physics during the second semester of their second academic year in the physics program. Before this course, students complete other science and mathematics courses in the first three semesters of the physics and physics education programs.

Modern Physics is a four-credit course that is compulsory for every physics and physics education student. The language of instruction is English and the total length of the course was almost 15 weeks per academic semester. The duration of each class was 50 minutes, and four sessions of the Modern Physics course were taught each week.

In this course, students were assessed by two midterms, quizzes, homework, and a final examination. Normreferenced evaluation was the main approach used for evaluating the students.

\section{Cases and contexts for quantization}

Quantization of physical observables such as light, energy, and angular momentum in quantum theory were the focus of this study. "Quantization" is an important phenomenon for quantum theory since its explanation brought about a new interpretation of experiment results. It also caused a paradigm shift from a classical perspective to quantum theory. Learning quantization correctly is important because accurate conceptions about quantization facilitate easier understanding of other quantum theory concepts.

Quantization explains the nature of light, energy, and angular momentum in the atomic world. It is not just a single concept taught in a Modern Physics or other quantum physics course. Since it is the underlying premise 
of quantum theory, it cannot be simplified under a single topic or title. In this study, we selected the contexts in which quantization was explained during the semester to identify students' mental models about quantization. These were as follows:

- Context 1: Photoelectric experiment.

- Context 2: Blackbody radiation and ultraviolet catastrophe.

- Context 3: Energy levels and atomic spectra.

- Context 4: Particle in a box.

- Context 5: Harmonic oscillator.

- Context 6: Atom (Bohr atom and the quantum mechanical model of atom).

\section{Description and selection of the participants}

The participants of this study were selected from undergraduate second-year physics and physics education students who were taking the Modern Physics course. In this setting, there were basically two kinds of student profiles: physics students from the college of arts and sciences, and physics education students from the college of education. Although students were enrolled in different departments, they took the same Modern Physics course given by the Department of Physics. The physics backgrounds of all the students in this course were the same because physics and physics education students take almost the same physics courses during their education.

Of all 98 students taking Modern Physics, 33 participants were purposely selected in order to gain more information about their understanding. In determining the number of students, our aim was to access a large number of students. The aim was not to have a representative sample, with respect to the "diversity" of the participants. For this reason, almost one third of the students in the class were chosen as participants in the study. However, two of the participants left the study in the middle because they did not have enough time to participate in the interviews regularly. For this reason, these students were omitted from the study. Table III shows the diversity of the participants with respect to their physics achievements and interests.

In selecting participants for the interviews, students' physics achievement and interests were the main considerations for diversity. During the first eight weeks of the semester, we obtained information about the students both inside and outside of the classroom. Students' achievements were examined via cumulative grade point averages (CGPAs), midterm-I results, and answers to conceptual questions in the quizzes. In addition, to what extent students' levels of interest in the course were determined by whether the students asked questions to the instructor inside and outside of the classes, answered the instructor's questions during the classes, discussed modern physics concepts during the breaks, and sat in the front or back of the lecture hall (and chatted with other students) during the
TABLE III. Participant selection.

\begin{tabular}{|c|c|c|}
\hline $\begin{array}{l}\text { Selection } \\
\text { domains }\end{array}$ & Selection criteria & $\begin{array}{l}\text { Number of } \\
\text { students }\end{array}$ \\
\hline \multirow{7}{*}{$\begin{array}{l}\text { By considering } \\
\text { students' } \\
\text { physics } \\
\text { achievement }\end{array}$} & CGPA $>2.80$ & 2 \\
\hline & $2.20 \leq \mathrm{CGPA} \leq 2.80$ & 2 \\
\hline & CGPA $<2.20$ & 2 \\
\hline & $\begin{array}{l}\text { Grade of midterm-I } \\
\text { above the average }\end{array}$ & 4 \\
\hline & $\begin{array}{l}\text { Grade of midterm-I } \\
\text { below the average }\end{array}$ & 4 \\
\hline & $\begin{array}{l}\text { Satisfactory explanations } \\
\text { in the quizzes }\end{array}$ & 3 \\
\hline & $\begin{array}{l}\text { Unsatisfactory explanations } \\
\text { in the quizzes }\end{array}$ & 2 \\
\hline \multirow{6}{*}{$\begin{array}{l}\text { By considering } \\
\text { students' } \\
\text { physics } \\
\text { interest }\end{array}$} & $\begin{array}{l}\text { Asking questions to the } \\
\text { instructor during and (or) } \\
\text { at the end of classes }\end{array}$ & 3 \\
\hline & $\begin{array}{l}\text { Answering the instructor's } \\
\text { questions in class }\end{array}$ & 3 \\
\hline & $\begin{array}{l}\text { Discussing modern physics } \\
\text { with others during the breaks }\end{array}$ & 3 \\
\hline & $\begin{array}{l}\text { Sitting at the front of the lecture } \\
\text { hall }\end{array}$ & 1 \\
\hline & $\begin{array}{l}\text { Sitting at the back of the lecture } \\
\text { hall and not interested } \\
\text { in the classes }\end{array}$ & 2 \\
\hline & Total No. of selected students & 31 \\
\hline
\end{tabular}

classes. In this way, Table IV presents the diversity of participants according to gender and department.

Basically, we interviewed two groups of participants: the core group and the secondary group. The students" "wish and convenience for spending extra time" determined the group membership of the 31 participants. This meant that in addition to being able to participate in four basic interviews during the semester, the core group of students had three extra interviews, in comparison with the secondary group of students.

The core group was composed of 8 students: four physics students and four physics education students. The reason for creating this group was to examine the mental models and their development in detail. Therefore,

TABLE IV. Department and gender of the students who participated in the study. The numbers in parentheses show the total number of students taking the course in the related group.

\begin{tabular}{lccc}
\hline \hline & \multicolumn{2}{c}{ Number of Number of Physics } \\
Physics & $\begin{array}{c}\text { Education } \\
\text { participants }\end{array}$ & $\begin{array}{c}\text { Total number } \\
\text { of participants }\end{array}$ \\
\hline participants & $9(25)$ & $4(11)$ & $13(36)$ \\
Females & $11(45)$ & $7(17)$ & $18(62)$ \\
Males & Total number & $11(28)$ & $31(98)$ \\
$\quad$ of participants & & & \\
\hline \hline
\end{tabular}


this core group was observed using a step-by-step process in which the detailed interviews were conducted topic by topic in an inductive way. The secondary group was composed of 23 students: sixteen physics students and seven physics education students. This group represented a wide range of students' achievement statuses, from low achievers to high achievers. The data of this group were also important in providing evidence of the categories under examination, since the models were first identified in the core group. Then, the secondary group was examined to see whether the same models existed or not. The secondary group was also examined during the semester, but in a deductive way, which excluded step-by-step examination of the concepts.

\section{Description of the instructor}

The instructor of the course is a full time professor in the department of physics. He specializes in astrophysics and has published several books and articles in that research area. He is student-friendly, smiling, and an enthusiastic professor. He always creates a relaxed environment for students to ask him questions if they need. He has been an instructor for 30 years, taught several physics courses for several years, and has taught the Modern Physics course for the last five years. He has an upper-level teaching certificate. By blending his experience in teaching and pedagogy knowledge, he is good at teaching physics.

\section{Description of the course setting}

The instructional methodology of this course was mainly instructor-centered. However, the instructor enriched the lessons by using several instructional techniques such as analogy, role play, questioning, and examples from daily life. In addition, he told stories related to the concepts, and discussed biographies of relevant scientists as well as pertinent history of science in the classes. He used these elements for different aims such as gaining students' interest, providing motivation to learn, and facilitating their understanding. When the instructor encouraged students to participate in classes, their participation was high. Especially when he used a questioning technique, the students were very enthusiastic about answering questions.

\section{B. Data collection methodology}

In this study, interviews, tests, and examination papers were used in order to find the answers for our research questions.

\section{Interviews}

In this study, semistructured interviews were conducted with the participants and instructor. These semistructured interviews were conducted outside the classroom setting and video recorded. Interviews were in both English and Turkish for the following reasons: (1) although the course instruction was in English, some students have difficulty making explanations in English, and (2) to remove the probable threats of students misinterpreting the questions in English. In addition, they were allowed to explain their ideas using multiple representations in written, drawn, or verbal formats. During their explanations, the students were also asked to think aloud as much as possible and to explain the sources of their answers.

Figure 1 presents the timetable for the interviews. Both of the groups (core and secondary) started the series with pre-interviews. However, while the core group was interviewed throughout the semester, the secondary group was interviewed near the end of the semester. So, each participant in the core group had seven interviews and each participant in the secondary group had four interviews. In the interviews, while the students were thinking aloud and answering questions, they were given their own copy of the interview protocol and papers on which to provide written explanations, drawings, etc.

The theory of relativity was taught during the first three weeks of the semester, followed by quantum theory. The interviews were conducted in line with the course schedule; they started in the ninth week of the semester and ended in the eighteenth week. The interview contents were as follows:

- Pre-interview: The pre-interview examined the participants' feelings, beliefs, ideas about the course, and the classroom environment.

- Interview I: The quantization of energy and light was examined in the contexts of blackbody radiation and the photoelectric effect (Contexts 1 and 2).

- Interview II: The quantization of energy was examined in the contexts of atomic spectra, the particle in a box, and the harmonic oscillator (Contexts 3, 4, and 5). We also examined the quantization of energy (Context 6.a1) and angular momentum (Context 6.a2) for the Bohr atom contexts.

- Interview III: The quantization of energy (Context 6.b1) and angular momentum (Context 6.b2) were examined in terms of quantum numbers in the context of a quantum mechanical model of an atom.

- Overall Interview: The overall interview was conducted to get detailed information about what students wrote the test, and to examine the consistency of students' explanations and see whether there was a change or not. It had the same questions as the test.

- Final Comprehensive Interview: Since Norman [7] explained the "instability" of mental models, the aim of this interview was to examine the "consistency" of development in the models over some period of time. For this reason, we asked the same questions as the test.

- Self-Evaluation Interview: We asked metacognitive questions intended to facilitate students' selfreflection about their own understanding. 


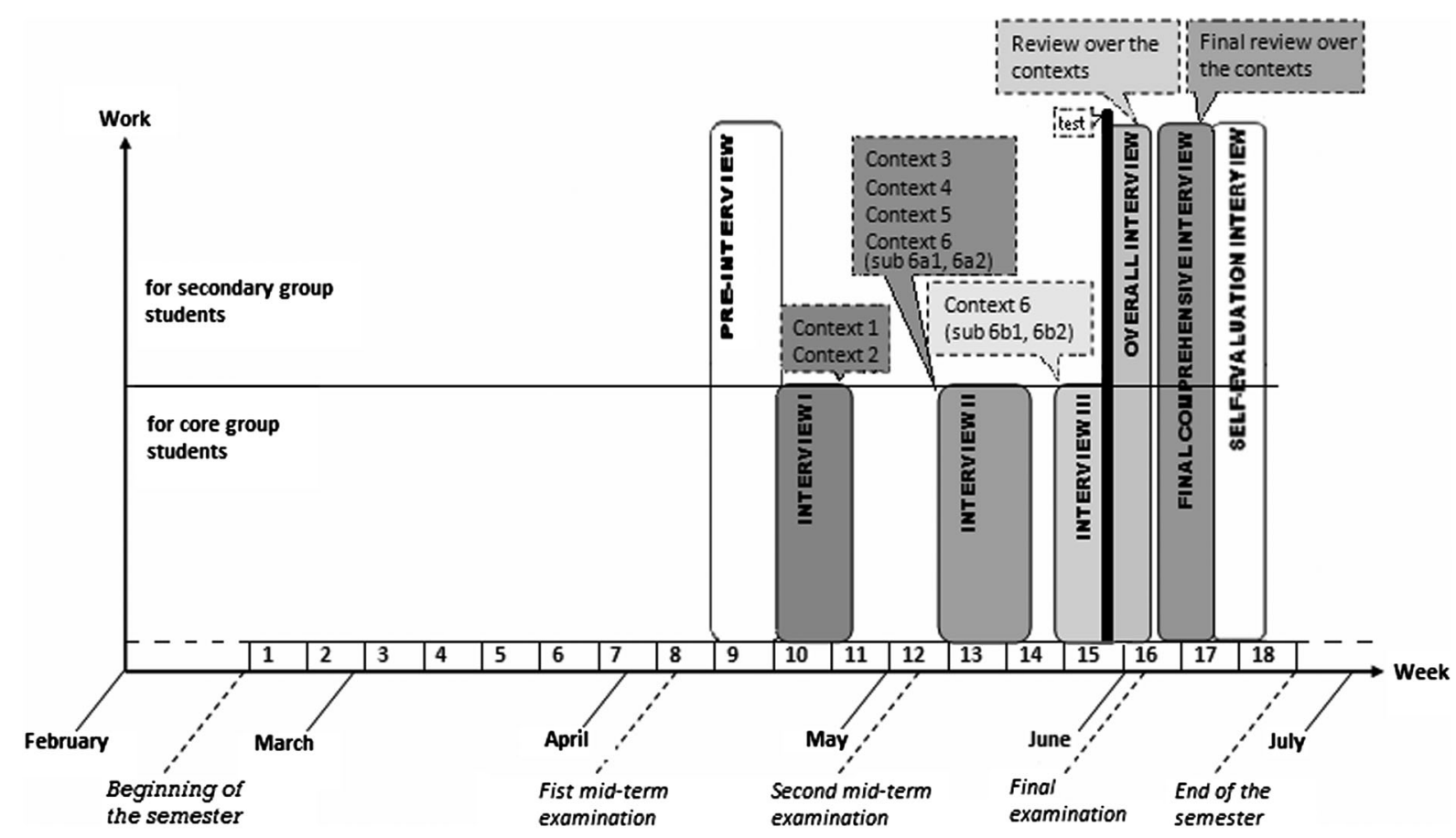

FIG. 1. Timetable for interviews with the participants.

At the end of the semester, we conducted a semistructured interview with the instructor in order to understand his experiences and obtain his opinions about students' understanding of the quantization of physical observables, the sources that shape their models, and his overall evaluation of students' motivation during the semester.

\section{Test}

After all of the topics about the quantization of physical observables were covered during the semester, the test was administered to all students in the class during the last week of the semester. This test was aimed to gather general information about students' understanding of the quantization of physical observables. The other aim was to provide a basis for the Overall Interview while also identifying mental models. The test was administered in class lasting for $30 \mathrm{~min}$.

\section{Examination papers}

Students in the Modern Physics course took three exams during the semester. These were Midterm I, Midterm II, and the Final Examination. There were both conceptual and mathematical questions on the exams. The instructor prepared all of the questions and evaluated all the papers. The three examination papers of the students were used to draw final conclusions about students' mental models for some contexts (i.e., Contexts 3 and 6).

\section{Data analysis of the interviews and test}

Data analysis is "the process of systematically searching and arranging" the data ([62], p. 153). The analysis of the data mainly consisted of three stages: (1) data reduction, (2) data display, and (3) conclusion or verification," as described by Miles and Huberman ([63], pp. 21-23).

In our data analysis, we considered the issues mentioned in Miles and Huberman ([63], pp. 60-63) and the following steps were taken: (1) the codes were named by considering their closeness to the concepts, (2) detailed definitions of the codes were made, and (3) double coding was done by a different researcher (external coder). Coding required difficult and long-term engagement at various times.

Interviews constituted the fundamental data of this research investigating mental models. Students' explanations in the test were integrated into data analysis during the determination of models. Finally, the examination papers were reviewed in order to determine the models for some students whose mental models were previously unclear.

\section{Steps of data coding}

Transcription. - All of the interview data were transcribed by one of the researchers. In addition, all of the participants' written and drawn artifacts produced in the course of our research were scanned and converted to electronic format.

Uploading the data into the program._- "Cases" were created in the program for each student, and all prepared data were transferred into the computer medium as well. This way, each student was matched with their data folder.

Reading.-Despite our familiarity with the data from the transcription period, all interview data for each participant was read twice after transcription. 
Determination of the codes (concepts). - Draft code lists were constructed based on previous quantum physics knowledge and the data obtained in this study.

Control of the code lists by the experts. - Three physicists (2 physics professors and 1 Ph.D student) and three physics educators ( 3 physics education professors) examined the constructed code list used for the interview analysis. The experts examined the codes in terms of "mutual exclusiveness" and "definition," as well as the "appropriateness" of the codes for our research aims. After revisions, a final code list was obtained (see Appendix A).

Coding.- Interview data were analyzed by means of a final code list. The unit of analysis for the investigation of mental models was "word(s)," defined as "a minimum meaningful chunk of a sentence, figure, or formula indicating quantization." The "content" of a "chunk" was determined as appropriate for the investigation of mental models, since each word and links among the words were the determiners for mental models. Therefore, we considered that although there might be more than one "chunk" corresponding to a code, a sentence can be coded only one time with the same code. In conclusion, each type of code may appear once per sentence, figure or formula (see Appendix B).

The coding of interview data started with the core group. Each student's interview data were analyzed context by context by matching the test and written or drawn materials from the interviews. This means that the quantization phenomenon was examined starting from Context 1 (photoelectric experiment) and by ending with Context 6 (Bohr and quantum mechanical model of an atom). For each context, students' explanations about the concepts of the quantization of physical observables were identified and named. After this process was completed for the core group students, the same process was followed for the secondary group.

\section{Constructing the models}

In our determination of mental models, students' definition of what quantization means was important, but it was not our focus. Their understanding of the phenomenon and their linking of the phenomenon with other physics concepts were considered to be the main focus along with their definitions of quantization. Coherency, or having a single conceptual framework, was the most important issue in our determination of a model among students' explanations. We considered students' statements about the links between concepts necessary for coherency. In other words, we were not just interested in checking whether the elements in a model existed, but we were looking for meaningful and organized use of these elements as a framework. We defined a "mental model" as a knowledge structure composed of elements coherently used to explain a phenomenon. Figure 2 presents the minimum conceptual elements for constructing mental models.

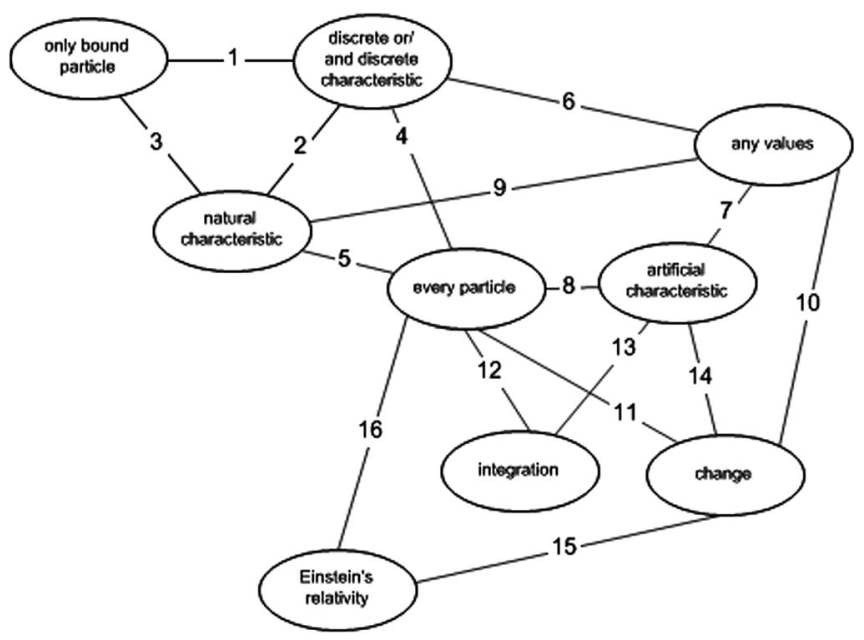

FIG. 2. Links among the model elements required for the coherency of models.

In our analysis, we accepted the elements "only bound particle, discreteness or (and) discreteness characteristic, and natural characteristic" as the minimum scientific elements in the construction of a scientific mental model (with links 1-2-3 in Fig. 2) about the quantization of physical observables. The other elements, "any values, artificial characteristic, Einstein's relativity, change, integration, and every particle" identify other models, but were designated as not exactly unscientific but irrelevant elements in the construction of scientific mental models about the quantization of physical observables. However, these elements were the main elements used in the construction of other (unscientific) mental models, rather than scientific models. In other words, the unscientific models were constructed with inappropriate use of the concepts. In this way, we identified mental models that did not have firm boundaries, but developed along with the ideas forming a coherent concept.

For example, St2 uses some OBP, D/DC, and NC codes by 3,11 , and 4 times, respectively, to explain the quantization of angular momentum in Bohr context (Context 6.a2). In this context, the codes were meaningfully linked to construct a framework (i.e., scientific mental model). However, there were some other structures that include additional codes that did not belong to a specific framework. For example, St 4 was a good example for this type of structure. The student uses AC, I, and EP (with 4, 3, and 2 times), respectively, to explain the quantization of angular momentum in the quantum atom (Context 6.b2). In this context, St4 uses also D/DC and NC, however, they are the explanations like scattering the words without making a meaning. That means some concepts do not belong to the coherent structure. We have focused on the coherently use codes (i.e., AC, I, and EP) to specify models by omitting the disconnected codes (i.e., D/DC, NC) in the determination of mental models. St1 presents another example 
about the determination of models. In Context 3 , the student uses four types of codes such as OBP, D/DC, $\mathrm{AV}$, and $\mathrm{C}$ with $2,10,3$, and 5 times, respectively, to explain the quantization of energy. Although this student uses more types of codes with several times, her explanations do not construct a framework to explain quantization. She has just used the words by scattering. That means the existence of some codes did not mean having a coherent structure. This type of structures, where the codes were incoherently used, was called "No Model". That means, in contrast to having coherent structures, students also have some fragmented knowledge, which cannot be called a mental model. We call this type of knowledge structure No Model (NM). These are disconnected knowledge elements, in other words, an incoherent use of fragmented elements such as p-prims, resources, facets, etc. [10]. They also include the direct recall of memorized elements without strong physically interpretive associations.

NMs were discriminated from "No Element (NE)" and "No Answer (NA)" because NMs include students making incoherent and unstructured explanations, whereas NAs show that a student does not give an explanation for the question. NE means that a student tries to answer the question, but states their ideas about quantum physics, the course and examination grades, feelings about being a physicist or a physics teacher candidate, etc., without providing any physical (scientific or unscientific) explanation.

\section{Reliability and validity issues}

In this study, many the techniques were used to provide validity and reliability and the precautions noted by LeCompte and Goetz [64] and Yildırım and Şimşek [65] were considered.

Credibility was addressed in this study by using prolonged engagement, peer debriefing, triangulation, member checking, and quasistatistics. Prolonged engagement is related to the duration of data collection. We also considered data saturation, meaning that no new information was obtained. Since this study was conducted with a large number of participants, the data became saturated at the end of the semester. For this reason, the duration of data collection was determined to be one semester (from the middle of February through the end of June), and then the data collection ended.

In this study, peer debriefing was done in two ways: (1) By a physics education researcher who participated from the beginning to the end of the study, and (2) by different physics and physics education researchers who participated at key points in the study by providing valuable feedback, including the validation of materials, analysis, and discussion of the study's results.

Since data triangulation decreases bias and other risks of associations occurring by chance in a research project ([66], p. 93), we used different types of data collection techniques in this study. In order to accurately record what a participant wanted to say we used member checking, which involves the participants giving approval of what a researcher records about them. This was done by requesting that each participant paraphrase their statement at the end of each question in the interviews as much as possible. In addition, by paraphrasing the participant's statements in a question format and asking "I understand..., am I right?" (5-6 times) in each interview, we secured the participant's agreement about their explanations. In this way, the participants provided an assurance about what they meant in their verbal and written explanations.

Quasistatistics is "the use of simple numerical results that can be readily derived from the data" ([66], p. 95). In this study, some descriptive statistics were used to present results.

Transferability was provided in this study by thick description and purposive sampling. All course settings, participants, and other important issues for this section were described in detail.

In this study, an external coder and the first author coded some pages individually and got $74.3 \%$ agreement. They discussed the disagreements in order to reach almost full agreement. In the second step, the external coder coded the new document by considering issues from the previous discussion after our first attempt to examine intercoder reliability. In our second attempt at intercoding, we obtained $90.7 \%$ agreement.

Miles and Huberman ([63], p. 63) suggested intracoding as a method for researchers to examine their consistency in coding. In this way, a researcher's consistency through time can be examined. The first author of this study examined a 5-6 page sample of data twice, waiting for almost a month between. An intracoder reliability coefficient of 0.94 was obtained at first. Then, after the examining disagreements with the previous coding, full agreement was obtained.

\section{E. Ethical issues}

Consent forms were distributed to students to inform them about the details of the research, and to get their written permission by signing the last part of the consent form. At the same time, we sought to respect the participants ([67], p. 551) by explaining the presence of an overt participant observer in their class and not deceiving them. Written permission was also obtained. Students' trust of the researchers was generated by providing detailed explanations and answering students' questions about the research.

A relaxed environment was provided for the students by preventing them from seeing or feeling the existence of the video camera or researcher in the classroom setting. This meant that the video camera and related setup were prepared in the lecture hall before the lectures. It was always located in the same place, at the back of the lecture hall where students could not see or focus on it during the 
data collection period. In addition, all interviews were recorded by video camera with participants' consent. Finally, for interviews and observations, video recordings, written materials, etc., were kept private. The confidentiality issue was strongly stressed and carefully explained to the students.

\section{RESULTS}

As we know, it is impossible to see students' mental models in their minds, and it is not practical to ask students directly what their mental models were [5]. Investigation of mental models requires making inferences from the data based on how students responded to questions about the phenomenon. For this reason, some quotes from the students' and instructor's explanations are given as evidences about students' models.

\section{A. Mental models}

Table $\mathrm{V}$ presents the summary of the mental models that students displayed about the quantization of physical observables. It also shows the common and distinguishing elements (see Appendix A) constructing these models. We named each mental model identified in this study due to the characteristics of its conceptual framework.

Each mental model seen in Table $\mathrm{V}$ is a specific composite of the codes (see Appendix C). In the following sections, we discuss mental models from scientific to unscientific. The aim of starting with the scientific mental models is to show clearly how students' knowledge structures diverge from scientific ones to unscientific ones due to a change of mental models.

\section{Scientific model (SM)}

The first model, which we call the "Scientific Model (SM)," is the scientifically accepted model. We identify students as having this model when they display the minimum concepts for a scientific explanation of quantization such as, "only bound particle, discreteness or (and) discreteness characteristic, and natural characteristic," and use them coherently in their explanation of the quantization of physical observables. The operational definition of this model states that a student who uses this model mentions the following:

- The quantization of physical observables such as energy and angular momentum is seen when a particle is confined in a region.

- The values of physical observables are restricted. The physical observables can have only discrete values and these values are only certain (allowed) values.

- This is natural for the atomic systems.

Figure 3 summarizes the use of SM across contexts to explain the quantization of light, energy, and angular momentum.

Among 31 students, only two of them used the SM in photoelectric effect context (Context 1). In particle in a box context (Context 4), a maximum of eight students used the SM. On the contrary, in blackbody radiation and ultraviolet catastrophe (Context 2), and harmonic oscillator contexts (Context 5), none of the students used the SM. Figure 3 implies that although the students have scientific mental models to explain the quantization of physical observables, its usage is limited across contexts when we consider all 31 participants.

Contexts 2, 3, 4, 5, 6.a1, and 6.b1 examine the quantization of energy. As can be understood from Fig. 3, most use of this model is seen in the particle in a box context (Context 4). One example of the use of the SM for energy levels and atomic spectra belongs to a physics student (St15). St15 is also very enthusiastic about learning modern physics, and she regularly attends modern physics lectures and enjoys them.

Investigator: All right, now, let's look at this situation (looking at the interview questions). Here there is an emission spectrum, and an absorption spectrum for a mercury atom. (examining the 1. question) "In an emission spectrum, what do the (colored) lines explain (for the visible region), or in an absorption spectrum what do the

TABLE V. Summary of mental models of quantization. Each mental model is a specific composite of the coherently use of these scientific and (or) irrelevant elements represented by the solid boxes.

\begin{tabular}{|c|c|c|c|c|c|c|c|c|c|}
\hline \multirow[b]{2}{*}{ Mental Models } & \multicolumn{3}{|c|}{ Scientific elements } & \multicolumn{6}{|c|}{ Irrelevant elements } \\
\hline & $\begin{array}{l}\text { Only bound } \\
\text { particle }\end{array}$ & $\begin{array}{l}\text { Discreteness }^{(1)} \text { or } \\
\text { (and) discreteness } \\
\text { characteristic }^{(2)}\end{array}$ & $\begin{array}{c}\text { Natural } \\
\text { characteristic }\end{array}$ & $\begin{array}{c}\text { Any } \\
\text { Values }\end{array}$ & $\begin{array}{c}\text { Artificial } \\
\text { characteristic }\end{array}$ & $\begin{array}{l}\text { Einstein's } \\
\text { relativity }\end{array}$ & Change & Integration & $\begin{array}{c}\text { Every } \\
\text { particle }\end{array}$ \\
\hline Scientific model & ! & ! & ! & & & & & & \\
\hline $\begin{array}{l}\text { Primitive scientific } \\
\text { model }\end{array}$ & & - & - & & & & & & - \\
\hline Shredding model & & घ & & घ & घ & & & & घ \\
\hline Alternating model & & & - & - & & & - & & - \\
\hline Integrative model & & & & & a & & & a & a \\
\hline Evolution model & & & & & घ & - & - & & घ \\
\hline
\end{tabular}




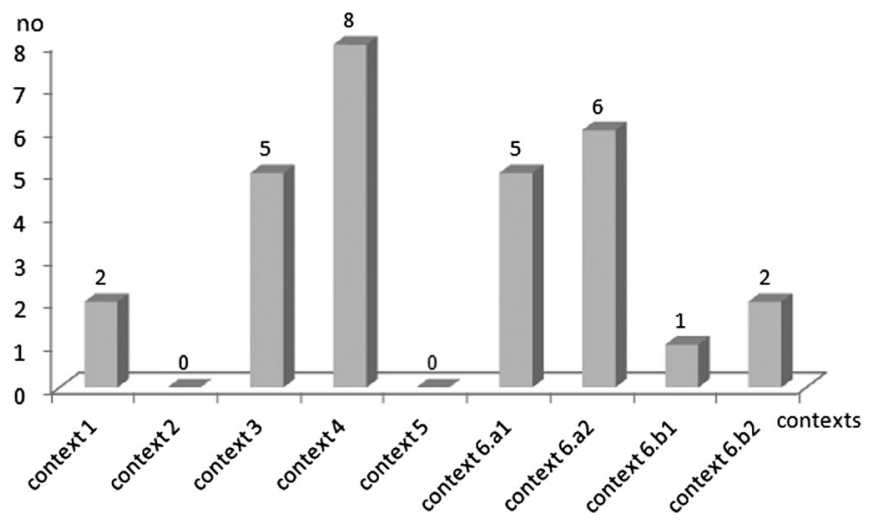

FIG. 3. The use of SM across contexts. A total of 29 students used this model.

dark lines explain? Why do the lines occur? Why do they have different colors (for the visible region) for emission spectra? Why are they dark for absorption spectra?" Do you have any idea about this issue?

St15: Yes, I have. This is like... Umm... (Showing the emission spectrum) An atom emits a photon when an atomic electron changes its orbit while jumping from an upper orbit to a lower orbit. These (showing the spectral lines) are the photons. The energy is not continuous-a certain amount of energy. For example, in the electron's movement from the third orbit to the second orbit, a photon can take the amount of energy between these energy levels that the electron has. Therefore, these lines occur.

I: OK. What do "dark" parts mean in an emission spectrum?

St15: Dark parts... Umm... That means an atom cannot emit a photon having that wavelength (by showing the dark part). Therefore, it is dark. In the absorption spectrum, it is the opposite. This means that if an atom absorbs a photon, this part seems dark (showing the dark part); the others seem colored.

I: All right, let's look at this (looking at the interview questions): Suppose the electron in the hydrogen atom obeys classical mechanics rather than quantum mechanics. What would you expect to observe in the spectrum? Why?

St15: It cannot behave as a classical particle! If it behaves classically, it must stick to the nucleus after turning and turning. But we do not see this. If it occurs, I would expect "light colors" here (by showing the spectrum). Umm... That means, I do not expect discrete lines like these ones (showing the spectrum figures in the interview protocol).

I: Can you clarify the "light colors" more?

St15: Not discrete colored lines. The photons with any wavelength could be emitted.

I: Do you mean like something continuous?

St15: Yes. At that time, energy could not be quantized in classical physics. It could be continuous. However, for example, here (showing the spectrum) energy is quantized since it has only certain values, not every value.
St7 is a very inquisitive student who tries to understand every physics concept she hears or reads and tries to make sense of them. Her explanation is as follows:

I: All right, what is "quantized energy" exactly?

St7: Quantized energy... Distinct energies, having only certain values... Umm... For example, I remember it from there; the instructor derived its formula. There is a particle in the box. When we examine a particle in the box whose wavelength is the de Broglie wavelength, when we use this information, we see there is an " $n$ " term in its energy formula. We see the "quantum number" and when we examine the formula, we see that it is possible just for certain energy levels. The reason is that the particle cannot have any wavelength because it is confined in a box. Either this one or this one (drawing "energy levels" on the particle in a box figure). It cannot have any wavelength. This is the reason. Because it cannot have every wavelength, it restricts the energy of the particle in a box.

Having a SM is important for explaining physical events correctly because the students displaying this model recognize that quantization is for bound systems and is the characteristic of nature itself. This issue is important for students' discrimination of classical and quantum physics. Although it is good to see students having scientific models, this research shows that the SM usage is limited both across contexts and in terms of the number of students who use the SM.

\section{Primitive scientific model (PSM)}

The Primitive Scientific Model (PSM) is an unscientific model. However, it also combines some scientific elements together with unscientific (irrelevant) ones in order to explain the quantization of physical observables. PSM contains the "discreteness or (and) discreteness characteristic, and natural characteristic" elements of SM, but the unscientific idea of "every particle." In this model, the students' conceptual framework is constructed around the following definitions. The student mentions the following:

- The values of physical observables are restricted. The physical observables can have only discrete values and these values are only certain (allowed) values.

- The quantization of physical observables is observed for all atomic particles, not for only bound particles.

- This is natural for atomic systems.

The difference between this model and the scientific one is students' inappropriate applications of "bound structure." Boundedness is an important element that should be considered in the quantization of physical observables such as energy and angular momentum. This part of the model discriminates itself from the SM in that the association between quantization with boundedness is not applied in PSM. Because this unscientific model seems to be closest to the SM, if this part of the model is recovered, students can still make coherent scientific explanations about the phenomenon. However, by 
considering the analysis of the atomic system and identification of the bound or unbound particles, it might not be easy to change the overall idea in mind by changing only the terms (bound-unbound particle). That means it requires an upper level cognitive process starting from the analysis then synthesizing the knowledge again to have a coherent understanding. Figure 4 represents the distribution of this model across contexts.

As seen in Fig. 4, this model was identified a total of 15 times. It is interesting that students explained the quantization of energy using this model only in Contexts 2 and 3, but not in Contexts 4, 5, 6.a1, and 6.b1.

The excerpt below shows a student's explanations about the quantization of light using the PSM:

I: How did Planck solve this problem?

St3: Umm... Planck... In his theory... He mentioned about quantized energy. Umm... Like energy blocks or energy packets, but I could not understand it well.

I: What is the reason for quantized energy?

St3: Particles... Umm... We know energy is quantized. This quantized energy is carried by photons, with energy packets... It is like that... Planck said energy and frequency are related. Einstein also said energy is quantized and it is carried by packets. They say similar things.

This student focuses on "photons," rather than "bound electron's," behavior as the reason for quantized energy. This shows that the student is in difficulty in the analysis of the system. Another student, St10, who uses the SM to describe the particle in a box and atom (only the Bohr atom part) contexts, uses the PSM in the energy levels context. In contrast to his scientific explanation in the particle in a box context, we see that this student does not indicate boundedness in the following excerpt:

St10: I remember that the instructor explained "quantum" was a Latin word. The energy was in the packets. Light transmits the energy packet by packet. I know quantized energy is "energy is in packets." I understand something like that. Umm... For example, if I lend some money to one of my friends, I can get my money with little

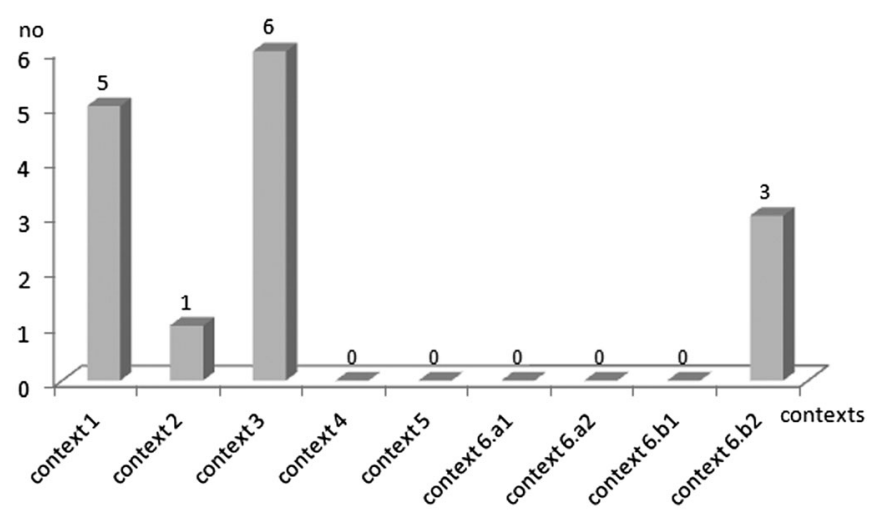

FIG. 4. The use of PSM across contexts. A total of 15 students used this model. amounts, such as 3 liras or 5 liras. I kid him and say, "I am a physicist, I must get my money with little amounts." It is something like that.

I: OK. You said, "energy is in packets." What can you say about the "energy levels"?

St10: Umm... Energy levels. The electrons in the atom have energy levels. Certain energies.

I: I want to turn back to your analogy. Your analogy was from the macro world. What can you say about...? Umm... What do you consider in order to explain quantization?

St10: Particles in the atomic systems. Here, photons.

St10 focuses on the same point with the previous student. This model is the closest to SM and seems to serve as a transition from an unscientific to scientific model. Therefore, analysis of the system and explicit stress on boundedness might be useful for students' in recognizing their conceptions and revising them to develop SMs.

\section{Shredding model (ShM)}

Another unscientific model identified in students' explanations of the quantization of physical observables is the "Shredding Model (ShM)." This model is called "shredding" because students' conceptual frameworks are constructed with an idea analogous to "cutting a cake into slices." This model can be defined based on a student mentioning the following:

- The physical observables are divided into quanta and have discrete values, just like dividing them into little particles.

- The values of the physical observables are not restricted, and quanta can take any value, just as you can take any size slice of cake.

- The quantization of physical observables is seen in all atomic particles, not for only bound particles.

- Quantization is not a natural characteristic of atomic systems, but rather an external manipulation of the values of the physical observables.

This model has even more unscientific elements than the PSM model. It was observed a total of 7 times in this study. Figure 5 shows the use of ShM across contexts.

As seen in Fig. 5, although the students used this model in the first five contexts, it was not observed in the atom context (Contexts 6.a1, 6.a2, 6.b1, and 6.b2). This model was only used by four students (all of them females) to explain the quantization of light and energy. Two of these four students used the ShM once across all contexts, and the other two students used the ShM more than once.

St27, a physics student who only used the ShM, associates the quantization of light with "dividing" in the following excerpt:

I: Well, do you remember the photoelectric experiment? St27: Yes. I think I remember it.

I: What was happening? Can you explain it for me?

St27: A photon comes and crashes to the surface, and it causes an electron to be emitted from the surface. 


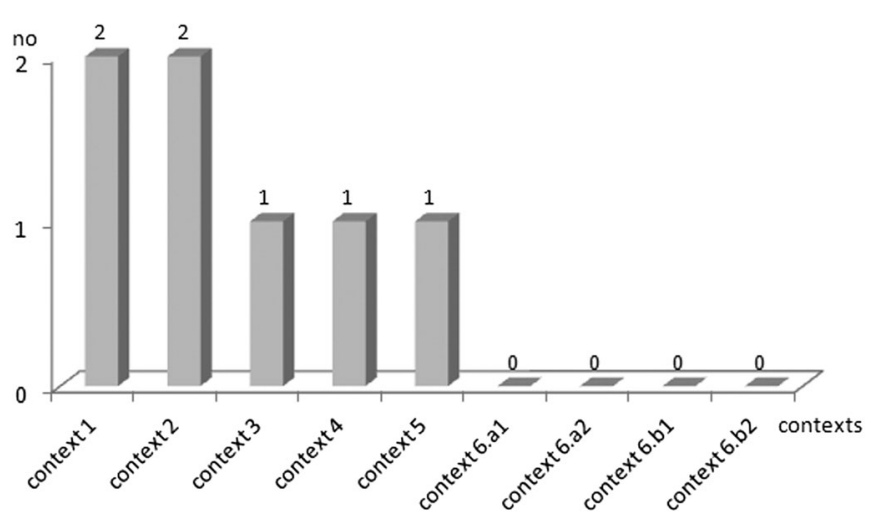

FIG. 5. The use of ShM across contexts. A total of seven students used this model.

I: Does every photon break off an electron?

St27: No, there is a limit for it, limit for the energy.

I: Do you say that, "every energy cannot break off the electron"?

St27: Yes.

I: Is it related to incoming light?

St27: Yes, the light's frequency affects it.

I: All right, can you mention something about quantization here? Is it in consideration?

St27: It is the disintegration of the energy, isn't it? That means the disintegration of the total energy... Umm... That means, not to take a constant value.

I: How does it happen? You explained, "dividing particles into their smallest components" here (in the test, looking at the test paper).

St27: Yes, yes. We mention it for the energy. For example, here we take the energy of the photon by dividing; this is quantization.

As can be seen in their explanations, the student ascribes a different meaning to "discreteness." St29, another physics student who only uses the ShM across contexts, explains the quantization of energy with this model. The sample excerpts are from the student's explanations in Contexts 1 and 4.

I: In addition to what you wrote on the test, would you like to say any other things about quantization?

St29: Quantization (speaking aside)...

I: You wrote, "if we think about for light." but you did not continue to explain here (looking at her test paper).

St29: Yes. We can think about light, and in addition, we can think about it for packets also.

I: What do they mean?

St29: It is something like packaging the light after dividing it into little particles... Umm (thinking)... Something like that.

I: Ok, let's explain it more. What do you mean by quantization exactly?

St29: We cannot quantize anything in classical physics, because the results were too silly and meaningless. In quantum theory, we quantize light, energy, and velocity.
That means we could quantize the light (quietly). In addition, we divide energy into smaller components and we quantize them.

I: OK, can you say something about the physical situation of the particle in a box?

St29: I know that when the energy of the electron is not enough, it behaves like a particle in a box.

I: Do you mean, "it may be a free particle when it has enough energy"?

St29: I think so, but I am not sure. I know there are free electrons in conductors.

I: OK, you said before that we quantize energy, velocity, etc. Now, what can you say about them?

St29: They are quantized. I think energy must be quantized.

I: Why is it quantized?

St29: Because we always see energy as discrete units in quantum physics. We divide the energy into little components and examine it like dividing light. I think that here, energy must be divided for the electron to exceed that energy and go out of the box. I guess quantization is required.

Students' explanations of the quantization of light and energy show that those displaying this model have difficulty with their conceptual understandings about both the phenomenon and its related concepts. They use only "discreteness," which is a scientific element, but ascribe a different meaning to it, such as dividing, disintegrating, slicing, etc. Also, other elements they used are irrelevant for explaining the quantization of physical observables. In addition, three of the students who use the ShM in a particular context do not use other models anywhere else. Therefore, the shredding model seems to have a robust influence on the construction of other models.

\section{Alternating model (AM)}

The next model we observed in this study was the "Alternating Model (AM)," in which students' conceptual frameworks about the quantization of physical observables are constructed around the "change" element. This natural change is seen in physical observables of every particle. The operational definitions for this model are that the student mentions that

- Quantization occurs like any kind of change. It is like a spontaneous change of values.

- There is no restriction for the values of the physical observables and so they can have any values.

- This is observed for all atomic particles, not only for bound particles.

- It is a natural characteristic of atomic systems

This change may depend on other physical observables. Therefore, the students using this model focus on continuity between the variables, and they perceive physical observables taking any values as "alternating." Using this 
alternating conception, students explain that physical observables do not have stable values because they are part of a dynamic system that is affected by external forces. Figure 6 shows the use of AM across contexts.

As seen in Fig. 6, this model was identified a total of 11 times. This model was mostly observed (5 times) in the particle in a box context (Context 4). The following excerpts indicate how the students who have this model explain the quantization phenomenon.

$\mathrm{St} 9$ is a physics student. She uses this model 6 times across contexts, and she does not use any other models. Although her use of this model is robust, she is nervous about her answers and has difficulty in remembering what she wrote on the test. Some of St9's explanations about the quantization of light are presented below.

I: All right, let's look at what you explained about quantization (looking at her test paper). You wrote "The values might be similar to each other, but they are different."

St9: I compared it with classical physics there. Why did I say that?

I: No, you compared it to classical physics below. "Quantized"... You said we haven't seen anything like that in classical physics (looking at her test paper together).

St9: (Smiling)...

I: You wrote, "It is in quantum physics... There is not quantization in classical physics"... Yes... You also wrote "particle" (looking at her test paper). Now, here, let's talk about "quantization." Explain verbally what you wanted to say here (on the test) exactly!

St9: Quantization... (Silence). Umm... Mass was changing.

I: How?

St9: That means, for example, I remember it only from mass. Or, like that... How can I say? It seems like... Mass gets a value when it already had one; this seems to me that it is quantized. I do not know if it is correct or not exactly... It is also the same for light... I don't know... (Silence)... (Smiling).

I: OK, well... You say, "the values are similar to each other but they are different," right?

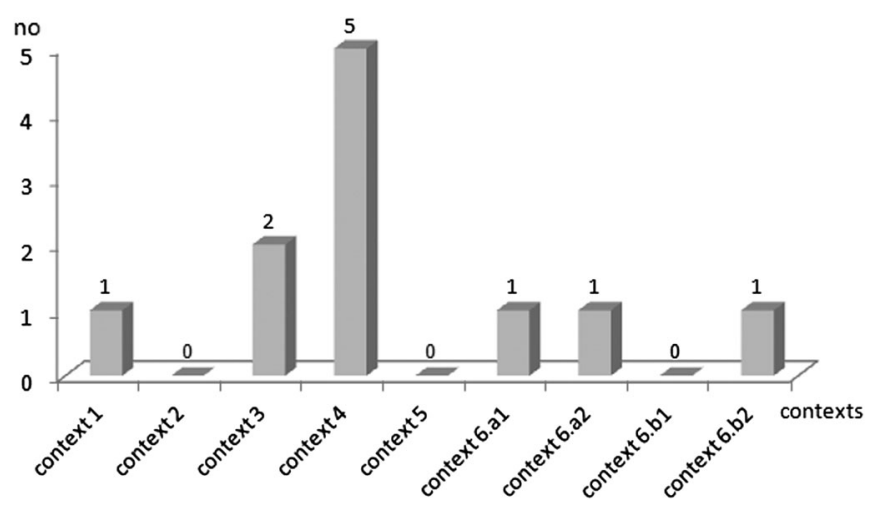

FIG. 6. The use of AM across contexts. A total of 11 students used this model.
St9: That means, for example, a mass is $10 \mathrm{~kg}$, but when it is quantized, we see it as nine or eight. I guess I wanted to say something like that here...

I: OK, you gave an example of mass, but you said that, "it is similar to light." When we say "light," let's continue with that. Do you remember the photoelectric experiment? What was happening in the photoelectric experiment?

St9: Light was coming, and then it was hitting and reflecting.

I: What was happening when it hit?

St9: It breaks off an electron.

I: Yes. If it has enough energy, it breaks off an electron from the surface. You know the photoelectric experiment is the experiment of Einstein. Can we mention about quantization here? Is there anything like that? What would you like to say?

St9: Here... Umm... Yes, I think it shows quantization because, for example, an electron stays at rest, and a light beam comes. Then it (electron) breaks away and changes its motion, creating a current. I think this shows an example of quantization.

Her explanations about the quantization of energy in the energy levels and atomic spectra contexts continue in a similar way. In both of these explanations, the student focuses on a "change" in the values of variables that naturally occur.

I: What does the quantized energy show here?

St9: Umm... The particle does not remain in its normal state. It does not stay the same, as we have known it. It does not keep its values. It changes. Actually, everything is not same as we see it. Its energy changes... It gets different values and becomes more different. Anything else (talking to herself)... Umm... Like that... (Smiling).

I: You say this change shows the quantization of energy, don't you?

St9: Yes. The energies are not constant; they are not same...

St21 still focuses on change while explaining quantization for the particle in a box with the following explanations:

I: OK. Well. What do you think about the physical meaning of "particle in a box"?

St21: (Silence).

I: What do we mean by "particle in a box"?

St21: Umm... The particle moves as a wave... de Broglie wave. Wavelength is related to the length of the box in order to keep the particle inside it.

I: Well, do you think this is just theoretical box, or does it have a physical meaning?

St21: I think it is theoretical. It is impossible to see such a thing.

I: OK, what do you want to say about this theoretical particle inside the box? What is it?

St21: Most probably it is an electron... Or, maybe a photon. 
I: Well, what do you think about the energy of this particle? Because you said, "it may be an electron, or a photon." Is the energy of that particle quantized?

St21: I think not. Energy is not quantized here!

I: Why is it not quantized?

St21: Because its energy is constant; it does not change. The particle just goes back and forth inside the box, so it is not quantized.

As can be seen in this student's explanation, they associate quantization with "change." So, St21 says, "there is not quantization" in the absence of a change.

Six of the 31 participants displayed this mental model. Whereas one student (St9) used the AM robustly in several contexts, the other five students used it in only one context (Context 4). Students' use of this model, especially in this context, may be attributable to an element indicating a "change" for quantization in the particle in a box experiment.

\section{Integrative model (IM)}

Another model that we identified in this study is the "Integrative Model (IM)." As with other unscientific models, this model includes students' use of, and links between unscientific elements to their explanations of the quantization of physical observables. Three out of 31 students used this model. Their conceptual framework about quantization is based on quantization as a mathematical idea. This means that instead of making sense of the quantization of physical observables as a physical event, they consider it to be a mathematical event determined by means of integrals, or integrating. Operational definitions for the IM include the student mentioning that

- Quantization is an integration process done to make the values of the physical observables continuous.

- Quantization of physical observables is observed for all atomic particles, not only for bound particles.

- Quantization is not a natural characteristic for atomic systems, but rather an external manipulation of the values of the physical observables.

Figure 7 shows students' use of this model across contexts.

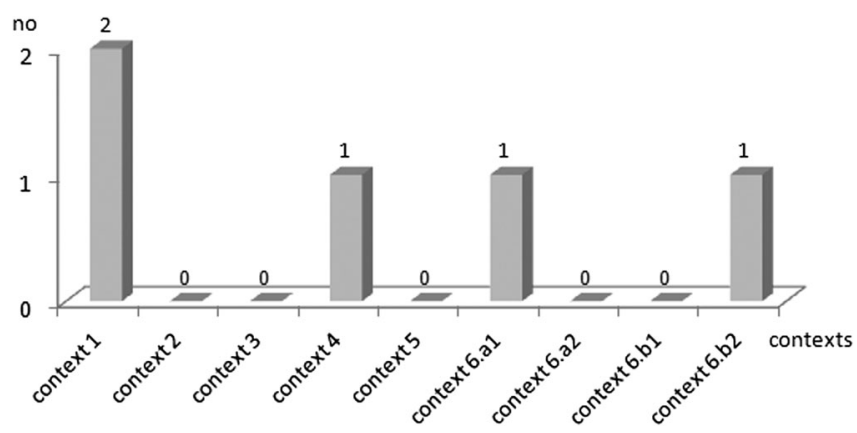

FIG. 7. The use of IM across contexts. A total of five students used this model.
As seen in Fig. 7, this model was identified a total of 5 times in the answers of three male students. Two of the three students used another model (SM) and fragments in different contexts, but one of the students (St28) uses only this model and fragments in his explanations of the quantization of physical observables. Some excerpts from the explanations of St 4 are presented below. He explains the quantization of light as follows:

I: Let's look at your test. You say on your test, "we quantize little particles in order to examine them because they are very little particles and to examine them, we are talking with some probability. So we need to examine these little particles in the packets" (looking at his test paper). Would you like to add anything here?

St4: (Smiling)... Umm... We are talking about the probabilistic situations in quantum physics. We cannot determine the location of a particle exactly. It is difficult to examine a single particle, so we consider a group of particles instead of a single particle. I understand "quantization" like that. I call this integration of particles "quantization." Am I right?

St28 gives similar explanations. He mentions some discrete quantities, however, his understanding about quantization is different from the scientific one. He tries to explain the quantization of energy as making pieces of energy continuous using mathematics.

I: Now, let's review what you wrote on the test.

St28: OK. After the quiz, actually before it, I examined the textbook about what quantum means. Actually, I examined the dictionary. It means, "how much" as I understand. But probably what you wanted to ask is not that exactly. Physically, as I understand, energy is in pieces, isn't it? For example, photons are similar; there is not unity. In any kind of quantization, we try to make it continuous. I understand it like that in my reading after the quiz.

I: What do you mean by, "making it continuous"? Why do we not accept it as it exists? In other words, why do we not accept the structure as discrete and instead try to make it continuous? What is the reason for this idea?

St28: Now, when we think about the wave function, we don't know where the electron is. We calculate that it is within some range with some probability. It is between plus infinity and minus infinity; it is certainly in there... (Thinking) This does not show a clear result to us. Actually, I cannot explain it exactly. So, it wants to get the whole. It is something like that. Actually, I cannot state it better.

I: Umm... You say, "by making the discreteness continuous" (silence).

St28: Yes. By making it continuous.

I: To summarize, "we are trying to make it continuous." St28: Yes.

I: OK. Well, you especially mentioned about the energy. Actually, we asked you which physical observables are quantized, and where and how we observed them here 
(on the test). Also, we requested that you give some evidence. While you were explaining quantization, you stated the energy first.

St28: Yes.

I: Yes... You started your explanation using the discreteness of energy. Would you like to continue talking about energy? Then, state again what you understand about the quantization of energy, and let's talk about it again. What do you mean?

St28: Umm... Quantization. That means, by making the discrete energy wave continuous, we can understand something there, and reach a conclusion.

I: OK, discreteness... That means a discontinuous situation.

St28: Yes, making the discontinuous situation "continuous." As I understand it, quantization means making a discontinuous wave or energy continuous.

...

St28: That means, for example, protons and neutrons in the nucleus, and electrons around them, move by vibrating in a modern model of the atom. We do not know the exact location, do we? Namely, to find its location, we quantize.

I: OK. Well, you said, "quantizing the discreteness" before...

St28: Making it continuous...

I: All right, where did we see it? That means quantization, you said. How did we make it continuous?

St28: It is too long... By writing the boundary conditions. For example, there is something in the particle in a box, also. Let's say that by writing boundary conditions between plus and minus infinity, we made it continuous.

I: OK, let's review what we mean by continuity again. If you explain it to me using a graph or mathematics, how do you make discontinuity "continuous"? How do you do that, exactly?

St28: By integrals... I could write the boundaries for the integral, I could write a sine function for the wave function and round it up to 1 . We can quantize by means of integrals like that.

By explaining quantization as associated with "integration," the students using this model consider quantization as a mathematical issue rather than a physical phenomenon.

\section{Evolution model (EM)}

Another model that we saw students use in this study was an unscientific model that we call the "Evolution Model (EM)." This model is inappropriate for quantum systems, and was the only model that we did not observe in the core group. There were only two male students in the secondary group who used this model. The operational definitions of this model is that the student mentions that:

- Quantization is a phenomenon of Einstein's theory of relativity.

- It occurs like any kind of change.
- The quantization of physical observables is observed for all atomic particles, not only for bound particles.

- It is not a natural characteristic of atomic systems, but rather an external manipulation of the values of the physical observables.

Figure 8 shows that these students only use this model in a single context - the photoelectric experiment context (Context 1).

This model was identified twice in students' explanations of the quantization of light. EM was not used in any of their explanations of the quantization of energy or angular momentum.

This model stresses a structural change in physical observables such as mass, energy, etc. In this property, it is also different from the AM. In the AM, change occurs in the values of physical observables. However, in EM, change occurs in the characteristics of physical observables, with it evolving into a different observable. This excerpt from St21, reflects how they understand the quantization of physical observables:

I: OK... Let's look at what you wrote about quantization. (Reading from his test paper) You said, "quantization is the energy of a particle," didn't you? You defined it in terms of its energy.

St21: Yes.

I: You also said, "quantization is the change of mass into energy when the material has the speed of light" (looking at his test paper).

St21: Is it correct?

I: (Silence)....

St21: Not correct! (Smiling).

I: Now, let's explain what you mean here exactly. You wrote quantization for energy on the test and you also wrote that mass might be quantized. You said, "It is the energy of a particle," also. What do these mean? Could you explain?

St21: Actually, I do not know exactly, teacher (smiling). That means...

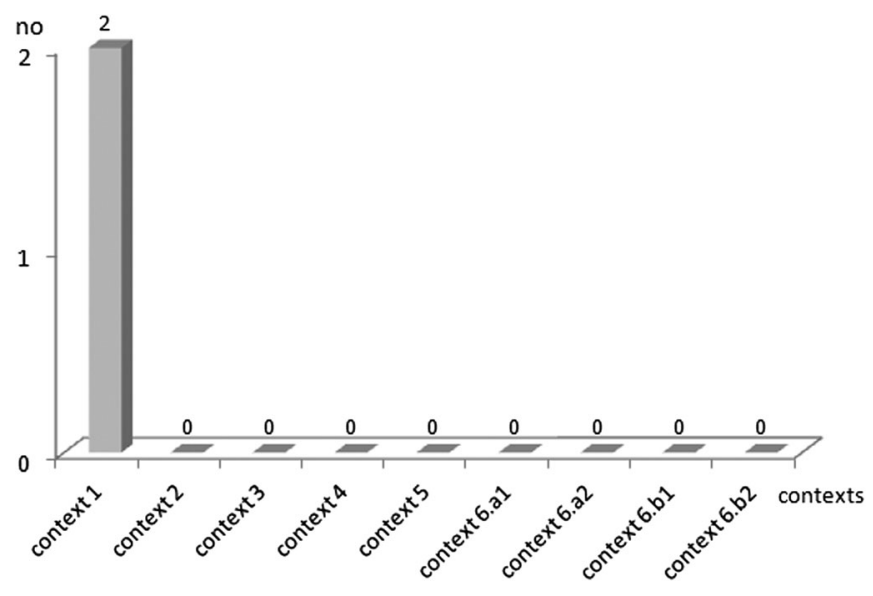

FIG. 8. The use of EM across contexts. A total of two students used this model. 
I: All right, if you consider energy in classical and quantum physics, is quantization a consideration?

St21: I should look at what I wrote there (Looking at his test paper).

I: (Looking at what he wrote on the test). You said that energy is equal to mechanical energy that is composed of kinetic and potential energies in classical physics. You defined kinetic energy. In quantum physics, you wrote, "when the material is quantized, the energy is $\mathrm{mc}^{2}$," didn't you?

St21: Yes.

I: You also wrote that, "kinetic energy changes due to the relativistic mass."

St21: Yes (nodding his head).

I: All right, what was your reason for saying that? I mean, this phenomenon-quantization-have you seen it in relativity topics?

St21: I know that... (Silence)... Umm... Yes, in the relativity chapter. I guess it was 2 nd chapter including mass, relativistic mass. They come to my mind. I know quantization is like that, so I wrote them.

I: OK, well, let's look at the last question on the test now. Here, we asked which physical observables were "quantized." For example, you wrote, "mass is quantized" and you continued to write other explanations. What do you mean here by "mass is quantized," exactly?

St21: By quantization, I mean the change of mass due to speed.

I: Do you say, "a change due to speed"?

St21: Yes. I think energy becomes mass.

I: Could you explain more? I could not understand well.

St21: Every mass has energy. Energy of the rest mass is $\mathrm{mc}^{2}$. When it has the speed of light, it has that energy.

I: Well, how does this particle have the speed of light? You mentioned about the energy of the particle!

St21: (Thinking)... We do this by accelerating.

I: OK, in this way is the energy quantized now?

St21: It is quantized.

I: Actually, you say, "we do quantize the energy by accelerating!"

St21: Yes.

I: All right, would you like to add any other things here?

St21: No.

In comparison to the other models, students' use of this model was very limited in terms of both the number of usages and number of contexts in which it was used.

\section{No model (NM)}

In contrast to having coherent structures, the students also have some fragmented knowledge, which cannot be called a mental model but called as No Model (NM). Figure 9 shows students' use of fragments without constructing mental models across contexts.

As can be seen in Fig. 9, some students used fragments in all of the contexts. NMs were used a total of 114 times in

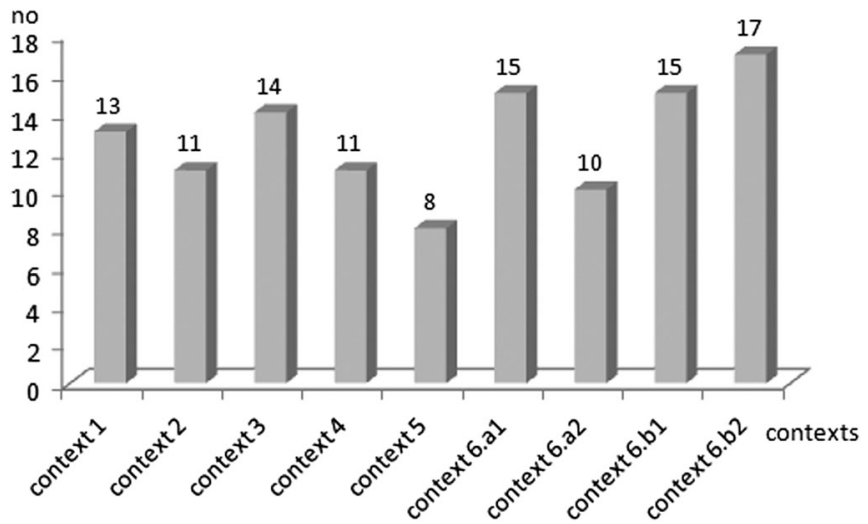

FIG. 9. The use of NM across contexts. Students used a total of 114 NM explanations.

279 instances of discussion. This is a very large number, since it constitutes almost half of the instances in this study. Figure 10 shows the comparison of NMs with the total number of all models across contexts.

Figure 10 summarizes that the use of fragments is greater than the total use of models. This result is not surprising, since models are coherent structures that require having conceptual frameworks to explain the phenomena, whereas the fragments are unlinked primitive elements. In a majority of instances, we observed that the students were more likely to respond with disconnected, one step reasoning based on poor understanding in each of the contexts.

\section{B. Characteristics of the mental models}

In this section, we focus on two characteristics of mental models: "nature" and "context dependency."

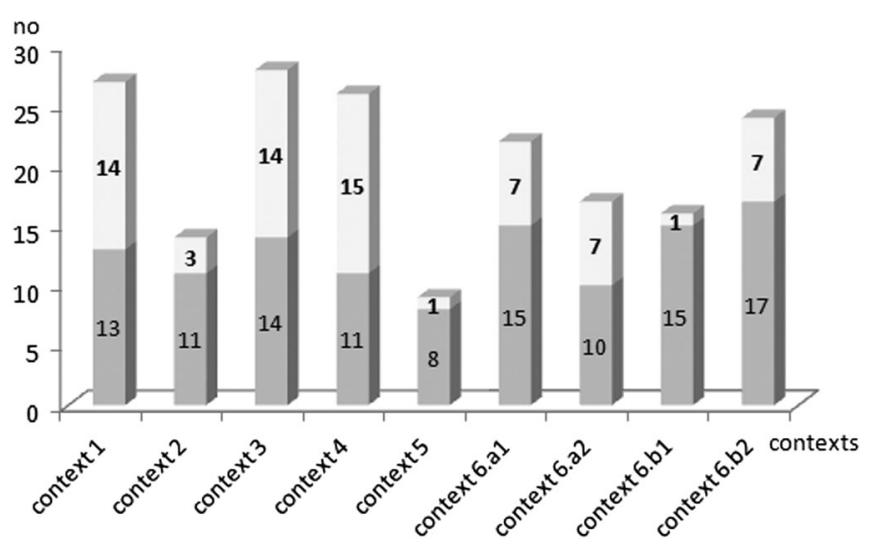

FIG. 10. Comparison between NMs and the total number of all models used across contexts. The lower part of the bar graph presents the number of instances where NMs were used in each context (a total of 114 times), and the upper part of the bar graph presents the number of instances where mental models were in each context (a total of 69 times). 


\section{Nature of mental models}

Six mental models about the quantization of light, energy, and angular momentum were identified in this study. Each model has a unique conceptual framework for quantization that is composed of scientific or unscientific elements. The one model which is composed of only scientific elements is considered to be scientific. The other five models are composed of a combination of scientific and unscientific elements, or only unscientific elements, and are thus considered to be unscientific.

A hybrid (blend) model gets some characteristics of two parental models and forms a new composite model that is different from the parental models [10,11]. In this study, determining whether a mental model has a pure or hybrid nature, we consider its "scientific" and "unscientific" elements. Therefore, we determine the purity or hybridity of the models by considering only their "scientific nature" as a reference. Table VI shows the pure and hybrid natures of mental models that students displayed for the quantization phenomenon.

The Scientific Model-SM-is a pure scientific model. It was mainly a few specific students who are enthusiastic about learning modern physics who used this model. They mainly gave explanations that they had thought through before the interviews, such as while they were studying, doing homework, etc. In addition to reasoning by linking concepts, the students using this model stated how the instructor explained the phenomenon in class. Also, students were sure about what they were explaining when they were using this model. When the students use the SMs, they state clear ideas about the discrimination between relativistic and quantum physics. Finally, we observed this model when the students had a correct understanding of the contexts. Students having SMs can use them on the spot together with previously thought out ideas since they use recall and reasoning together while answering the

TABLE VI. Pure or hybrid nature of the models.

\begin{tabular}{lccc}
\hline \hline & $\begin{array}{c}\text { Number of } \\
\text { scientific } \\
\text { elements } \\
\text { in model } \\
\text { structure }\end{array}$ & $\begin{array}{c}\text { Number of } \\
\text { unscientific } \\
\text { (irrelevant) } \\
\text { elements in } \\
\text { model structure }\end{array}$ & Nature of models \\
\hline SM & 3 & 0 & $\begin{array}{c}\text { Pure scientific model } \\
\text { Hybrid unscientific } \\
\text { model }\end{array}$ \\
ShM & 2 & 1 & $\begin{array}{c}\text { Hybrid unscientific } \\
\text { model } \\
\text { Hybrid unscientific } \\
\text { model }\end{array}$ \\
IM & 1 & 3 & $\begin{array}{c}\text { Pure unscientific } \\
\text { model } \\
\text { EM }\end{array}$ \\
EM & 0 & 3 & $\begin{array}{c}\text { Pure unscientific } \\
\text { model }\end{array}$ \\
\hline \hline
\end{tabular}

questions. For example, St18 states his explanation based on previously thought out ideas:

St18: I have written them by thinking about the nature of light (on the test). The light contains packets, quanta... So I have written all of them by thinking about these packets.

The Primitive Scientific Model-PSM-is a hybrid unscientific model. It is the closest model to the SM because of its composition, but it still contains unscientific elements. The PSM model is constructed because of students' nonidentification of "boundedness" and overgeneralizations about the physical observables of every particle. At this point, the students seem to have some conceptual difficulties understanding the quantization phenomenon. This point also shows that the students have some conceptual problems about the physical explanations for each context. The students using this model are not confident about their learning. One example is from St20. He stresses concerns about his confidence in his explanations:

St20: I think that my answers are not correct...

The Shredding Model-ShM-is a hybrid unscientific model. The students who use this model have a very different understanding of the quantization phenomenon. Their understanding the quantization of physical observables is shaped around the idea that the quantization of physical observables is like "slicing a cake." As Vosniadou and Brewer [68] explained, students' on the spot explanations give some clues about their mental models. These cues included "stopping during the interview to think," "smiling as if asking 'am I right?"“, etc. In addition, students' degrees of certainty show that they are generally not sure about their explanations. One example belongs to St27. She seems very reluctant to examine the phenomenon across contexts. She is so unsure about her statements:

St27: I think we should not discuss it for the other situations.

I: Why?

St27: (Smiling) Because I think all of my previous answers are wrong. I cannot be sure about them.

The explanations of St27 and St29 are as follows:

St27: Umm... I need to think... Umm... Quantization... Discrete energies... It is so complex... I will leave to work in physics (showing discomfort)!

St29: I don't know... I just feel that I talk nonsense about the same things (with dissatisfied manner).

The most important issue for this model is that students have some problems in discriminating between the concepts of classical, quantum, and relativistic physics, as well as their contexts.

The Alternating Model-AM-is a hybrid unscientific model. Similar to ShM, this model of quantization diverges significantly from the SM. In this case, students' models are developed around the idea of "change." In addition, students make more on the spot explanations and they 
are nervous about their answers while using this model. For example, St24 states that

St24: I do not know if my answers are correct or not. I never can be sure about them. Maybe they are correct, maybe not... When I see this concept (quantization), I cannot be sure about my knowledge.

They have conceptual difficulty with the concepts in different contexts. In AM, we also observed that students make mainly on the spot explanations. One of the students (St9) who uses the AM regularly across contexts, gives explanations indicating "on the spot explanations" and shows conceptual difficulty with some concepts:

St9: Umm... I don't know... I haven't thought about it before.

St9: I have no idea about why I explained it like that there...

St9: I don't know exactly whether it is quantized or not.

St9: I am not sure, but I feel that I cannot construct the concepts. I do not feel that I understand it well. Maybe I am guilty because I did not study too much.

The Integrative Model-IM-is a pure unscientific model. Students' understandings about the quantization of physical observables are shaped around the idea of "the integration of small parts." One of the different characteristics of this model is students' mathematical interpretation of the physical phenomenon. In contrast to other models, students using the IM think that quantization is a mathematical way of using integrals. The students who use this model are also not sure about their explanations. As with the other unscientific models, students using the IM have conceptual difficulties with the concepts across contexts.

The Evolution Model-EM-is a pure unscientific model. In this case, students' models are developed around the idea of "evolving." Students' key concept in using this model was the "speed of light." They use some ideas of the theory of relativity while explaining quantization phenomenon. Students have problems in discriminating Einstein's relativity and the ideas of quantum theory. In addition, they are also not sure about their explanations. The excerpt below belongs to St21 who uses EM. He states his guess before his explanations, and then explains the phenomenon. This also indicates his on the spot thinking while he is giving his explanations. St11 also gives similar explanations:

St21: It is quantized...

I: How do you explain it?

St21: I just guess with a $50 \%$ probability (smiling).

St11: More speed means more energy... But I want to remind you that all of my explanations are "based on my mind." That means $90 \%$ is wrong (smiling).
The last important finding is about the use of scientific and unscientific models. The findings show that students who use the SM in one or more contexts used mainly No Models-NMs - when they do not use models; however, the students who use unscientific models (PSM, ShM, AM, IM, and EM) use mainly No Elements-NEs-when they do not use models, and sometimes they do not answer the questions (No Answers-NAs).

\section{Context dependency of mental models}

Studying students' mental models in different contexts is important in order to see the context dependency of mental models. As identified in previous studies [10-13,16,69], students' mental models were also found to be context dependent in our current research. This means that students may use different models for understanding a phenomenon in different contexts. We examined this context dependency especially with respect to students' explanations of the quantization of energy, which is presented in Table VII.

For example, Contexts 2, 3, 4, 5, 6.a1, and 6.b1 are those that discuss the quantization of energy. We identified that while students can explain the quantization of energy using the SM in one context, they also use some unscientific models (PSM) in the other contexts (St2, St3, St7, and St10). One of the students (St1) used different unscientific models (ShM-AM) in different contexts. These findings indicate importance of discussing different model states.

We know that people can hold two or more "inconsistent" mental models together in the same domain [5]. More specifically, students may use different models for the same phenomenon in different contexts. We call this a "mixed state," following Bao [13], Hrepic [10,11] and Hrepic, Zollman, and Rebello [12]. If a student's model is used robustly across contexts, it is called "pure state" $[10,12,13]$. In a mixed model state, students hold different mental models for a situation at the same time, and use them inconsistently $[10,12,13]$. In this study, the students use different models at the same time across contexts. For example, we see in Table VII that St1, St2, St3, St7, and St10 have mixed model states since these students use the SM and PSM together. In addition, St1 uses two different unscientific models, which are the ShM and AM, both of which are hybrid unscientific models. Since they are different hybrid models, hers is also a mixed state model.

In addition, we can see from the table that none of the students use models in all contexts simultaneously. They may sometimes use models, and sometimes fragments. They sometimes do not answer the questions or state any physical explanations. In our examination of students' model usage, we saw that nineteen students had pure model states in the quantization of energy case. The last seven students did not use any model to explain the quantization of energy.

In Table VII, we also see the robustness of students' ideas. For example, St9 uses the AM in three contexts about 
TABLE VII. Context dependency of the models. F: Female, M: Male, PHYS: Physics student, PHED: Physics education student, NA: No answer, NE: No element, NM: No model. SM: Scientific model, PSM: Primitive scientific model, ShM: Shredding model, AM: Alternating model, IM: Integrative model, EM: Evolution model.

\begin{tabular}{|c|c|c|c|c|c|c|c|c|c|c|c|}
\hline CODE & GENDER & DEPT & Context 1 & Context 2 & Context 3 & Context 4 & Context 5 & Context 6.al & Context $6 . \mathrm{a} 2$ & Context 6.bl & Context 6.b2 \\
\hline ST1 & $\mathrm{F}$ & PHED & NM & ShM & $\mathrm{NM}$ & $\mathrm{AM}$ & NM & NM & NM & $\mathrm{NE}$ & NM \\
\hline ST2 & M & PHED & PSM & NM & PSM & SM & NM & NM & SM & NM & $\mathrm{SM}$ \\
\hline ST3 & M & PHYS & PSM & PSM & NM & SM & NM & SM & SM & NM & NM \\
\hline ST4 & M & PHYS & IM & NM & NM & NM & $\mathrm{NE}$ & NM & SM & $\mathrm{NE}$ & IM \\
\hline ST5 & M & PHED & NM & NM & NM & NM & $\mathrm{NE}$ & $\mathrm{IM}$ & $\mathrm{SM}$ & NE & NM \\
\hline ST6 & M & PHYS & NM & NM & SM & SM & NM & NM & NM & NM & NM \\
\hline ST7 & $\mathrm{F}$ & PHYS & PSM & NM & PSM & SM & NM & SM & NM & SM & NM \\
\hline ST8 & M & PHED & $\mathrm{NM}$ & $\mathrm{NE}$ & NM & $\mathrm{NE}$ & NM & SM & NM & NM & NM \\
\hline ST9 & $\mathrm{F}$ & PHYS & $\mathrm{AM}$ & $\mathrm{NE}$ & $\mathrm{AM}$ & $\mathrm{AM}$ & $\mathrm{NE}$ & $\mathrm{AM}$ & $\mathrm{AM}$ & NM & $\mathrm{AM}$ \\
\hline ST10 & M & PHYS & NM & $\mathrm{NE}$ & PSM & SM & NA & SM & SM & NM & NM \\
\hline ST11 & M & PHYS & EM & $\mathrm{NE}$ & NM & NM & NA & NM & NM & NM & PSM \\
\hline ST12 & $\mathrm{F}$ & PHED & NM & $\mathrm{NE}$ & PSM & $\mathrm{NE}$ & NA & NM & NA & NM & NM \\
\hline ST13 & $\mathrm{F}$ & PHYS & NM & NE & NM & $\mathrm{NE}$ & $\mathrm{NE}$ & NM & $\mathrm{NE}$ & $\mathrm{NE}$ & NM \\
\hline ST14 & $\mathrm{F}$ & PHYS & NM & $\mathrm{NE}$ & NM & $\mathrm{NE}$ & $\mathrm{NE}$ & $\mathrm{NE}$ & $\mathrm{NE}$ & NE & $\mathrm{NE}$ \\
\hline ST15 & $\mathrm{F}$ & PHYS & NM & NM & $\mathrm{SM}$ & SM & NM & $\mathrm{SM}$ & NM & $\mathrm{NE}$ & $\mathrm{NM}$ \\
\hline ST16 & $\mathrm{F}$ & PHED & NM & $\mathrm{NE}$ & $\mathrm{NM}$ & NM & $\mathrm{NE}$ & NM & NM & NE & $\mathrm{NE}$ \\
\hline ST17 & M & PHYS & PSM & NM & NM & NM & $\mathrm{NE}$ & NM & $\mathrm{NE}$ & $\mathrm{NE}$ & PSM \\
\hline ST18 & M & PHYS & SM & NM & $\mathrm{SM}$ & SM & NA & NM & SM & NM & NM \\
\hline ST19 & M & PHYS & NM & $\mathrm{NE}$ & PSM & NM & NA & NM & NM & NM & $\mathrm{NE}$ \\
\hline ST20 & M & PHYS & $\mathrm{NE}$ & $\mathrm{NE}$ & PSM & NM & NA & NM & $\mathrm{NE}$ & NM & NM \\
\hline ST21 & M & PHYS & EM & $\mathrm{NE}$ & $\mathrm{NM}$ & $\mathrm{AM}$ & NA & $\mathrm{NE}$ & $\mathrm{NE}$ & $\mathrm{NE}$ & $\mathrm{NE}$ \\
\hline ST22 & M & PHED & SM & NM & NM & $\mathrm{AM}$ & NA & $\mathrm{NE}$ & $\mathrm{NE}$ & NM & PSM \\
\hline ST23 & $\mathrm{F}$ & PHYS & NM & NM & $\mathrm{NE}$ & $\mathrm{AM}$ & NA & $\mathrm{NE}$ & NA & $\mathrm{NE}$ & $\mathrm{NE}$ \\
\hline ST24 & $\mathrm{F}$ & PHED & NA & NM & $\mathrm{AM}$ & NA & NA & $\mathrm{NE}$ & NA & $\mathrm{NE}$ & NM \\
\hline ST25 & M & PHED & PSM & $\mathrm{NE}$ & $\mathrm{SM}$ & $\mathrm{SM}$ & NA & NM & NM & $\mathrm{NM}$ & SM \\
\hline ST26 & M & PHED & $\mathrm{NE}$ & $\mathrm{NE}$ & NM & NM & NA & $\mathrm{NE}$ & NA & $\mathrm{NE}$ & NA \\
\hline ST27 & $\mathrm{F}$ & PHYS & ShM & ShM & $\mathrm{NE}$ & NM & NA & $\mathrm{NE}$ & NA & $\mathrm{NE}$ & NM \\
\hline ST28 & M & PHED & IM & $\mathrm{NE}$ & $\mathrm{NE}$ & IM & $\mathrm{NE}$ & $\mathrm{NE}$ & $\mathrm{NE}$ & $\mathrm{NE}$ & NM \\
\hline ST29 & $\mathrm{F}$ & PHYS & ShM & $\mathrm{NE}$ & ShM & ShM & NA & $\mathrm{NE}$ & $\mathrm{NE}$ & $\mathrm{NE}$ & $\mathrm{NE}$ \\
\hline ST30 & $\mathrm{F}$ & PHYS & $\mathrm{NE}$ & $\mathrm{NE}$ & $\mathrm{NM}$ & $\mathrm{NM}$ & ShM & NM & $\mathrm{NE}$ & $\mathrm{NM}$ & NM \\
\hline ST31 & M & PHYS & NM & $\mathrm{NE}$ & SM & NM & NM & NM & NM & $\mathrm{NM}$ & NM \\
\hline
\end{tabular}

the quantization of energy and thus uses the same knowledge structure robustly. Also, as another example, St15 uses the SM in three contexts as well and gives scientific explanations about the quantization of energy. These robust models seem stable and might become context independent after a time.

\section{Reconsideration of the results}

To summarize, second-year physics and physics education students displayed six different mental models about the quantization phenomenon. Among the mental models identified, the most used model was the SM (used a total of 29 times). Although having students use scientific models more often than unscientific ones is a desirable outcome, this was quite a small number when we consider the total of 279 instances examined in this study. Table VIII presents the use of all models across contexts.

The diversity of the models displayed in this study was greatest in Context 1 (six different models), and least in Contexts 5 and $6 . b 1$ (one type of model). This might be interpreted as the result of students' greater familiarity with the photoelectric effect context than the harmonic oscillator and the quantum atom contexts.

In addition to the identified models, the instructor explains his ideas about students' understandings of the quantization phenomenon. The instructor thinks that the richness of a student's explanations varies due to their models. The following excerpts present the ideas of the instructor:

Instructor: This (quantization) is not such an easy concept for students to understand. Its comprehension is difficult. They got some good grades in the exams, however, they have some misconceptions and missing conceptions brought from high school physics classes related to the phenomena. These previously learned conceptions make it hard for students to understand the phenomena. In previous lessons, the students learned "continuous physics," but when they now pass onto "quantized observables," new concepts are difficult for them. If they cannot model the new concepts in their minds, 
TABLE VIII. Summary of the frequency of mental models and other structures across contexts.

\begin{tabular}{|c|c|c|c|c|c|c|c|c|c|c|}
\hline CONTEXTS & 1 & 2 & 3 & 4 & 5 & $6 . \mathrm{a} 1$ & $6 . \mathrm{a} 2$ & 6.b1 & $6 . b 2$ & Total number of MOS \\
\hline \multicolumn{11}{|c|}{ MODELS and OTHER STRUCTURES (MOS) } \\
\hline MODEL 1: Scientific Model & 2 & 0 & 5 & 8 & 0 & 5 & 6 & 1 & 2 & 29 \\
\hline MODEL 2: Primitive Scientific Model & 5 & 1 & 6 & 0 & 0 & 0 & 0 & 0 & 3 & 15 \\
\hline MODEL 3: Shredding Model & 2 & 2 & 1 & 1 & 1 & 0 & 0 & 0 & 0 & 7 \\
\hline MODEL 4: Alternating Model & 1 & 0 & 2 & 5 & 0 & 1 & 1 & 0 & 1 & 11 \\
\hline MODEL 5: Integrative Model & 2 & 0 & 0 & 1 & 0 & 1 & 0 & 0 & 1 & 5 \\
\hline MODEL 6: Evolution Model & 2 & 0 & 0 & 0 & 0 & 0 & 0 & 0 & 0 & 2 \\
\hline NO MODEL: No Model & 13 & 11 & 14 & 11 & 8 & 15 & 10 & 15 & 17 & 114 \\
\hline NO ELEMENT: No Element & 3 & 17 & 3 & 4 & 8 & 9 & 9 & 15 & 6 & 74 \\
\hline NO ANSWER: No Answer & 1 & 0 & 0 & 1 & 14 & 0 & 5 & 0 & 1 & 22 \\
\hline Total number of students & 31 & 31 & 31 & 31 & 31 & 31 & 31 & 31 & 31 & 279 \\
\hline
\end{tabular}

they cannot learn them easily. I do not say, "they learned quantization completely," but I believe they learned the basic ideas about it. They have learned that the energy levels of a hydrogen atom are quantized, angular momentum is quantized, etc. Then, I think they can construct the other ideas of quantum physics based on this knowledge. I think they got the main ideas.

Instructor: Students' explanations vary. A student who understands well can model quantization better and explain it better. For example, in the class, I made an analogy about the flow of water drops from a tap to indicate the discreteness. When you let the water flow fast, we cannot see the discreteness at that point. This point can be considered as Newtonian physics. I think that the students who understand quantization correctly can remember this analogy or construct other analogies, and explain quantization correctly.

To summarize, in our study of 279 instances, the most dominant event was the use of NM. Since mental models are complex and coherent structures, students sometimes prefer to use fragments, either consciously or unconsciously. Fragments are the most dominant structures used by students $(\sim 40.9 \%)$. The percentage of instances where students used models $(\sim 24.7 \%)$ is close to the percentage times where none of the fragments were used $(\sim 26.5 \%)$.

\section{CONCLUSION, DISCUSSION, AND IMPLICATIONS}

\section{A. Conclusion and discussion}

Conclusion 1: Second-year physics and physics education students display six different mental models about the quantization of physical observables. These are the Scientific Model (SM), Primitive Scientific Model (PSM), Shredding Model (ShM), Alternating Model (AM), Integrative Model (IM), and Evolution Model (EM).
Quantization is an important phenomenon for quantum theory. It is the precious result of different experiments that caused a paradigm shift in physics. In this vein, our investigation into students' mental models about the quantization of physical observables shows how they construct and organize their knowledge about quantum theory. For example, the SM indicates a coherent structure that contains scientific elements and links that are scientifically constructed. The other models (PSM, ShM, AM, IM, and EM) also indicate coherent structures, but they combine scientific and unscientific concepts together, use totally irrelevant concepts, or rely on wrong and missing connections. Therefore, in comparison to the SM, the other identified mental models are unscientific models used to explain quantization of physical observables. As Norman [7] explained, mental models may be unscientific, because people may hold superstitious behavior patterns in order to save mental energy. In addition, as Itza-Ortiz, Rebello, and Zollman [21] implied in their study, students' unscientific models should not considered "errors," but rather the result of their "own internal consistencies."

Conclusion 2: Identification of unscientific mental models shows that students have difficulty with quantum concepts.

This study, with its large number of students and having been conducted over a large number of contexts and concepts, shows that students have difficulty in (1) making sense of quantum concepts, (2) discriminating between concepts, (3) linking concepts, and (4) putting physical meaning into mathematical explanations. This result is compatible with previous research [13,28,29,33,35-41,43], because many studies have identified such types of problems in students' understandings of quantum concepts. One of the reasons for these difficulties might be the nature of quantum concepts, which are abstract, counterintuitive, and mathematical. The other reason might be students' epistemological and ontological beliefs about quantum theory. For example, students stick to classical interpretations when a quantum variable has a classical counterpart. 
Also, if the quantum concepts were not similar to classical concepts, students did not build physical understandings of the mathematics [13]. In this study, we observed that students consider quantum physics as a total contrast to classical physics. Therefore, while making explanations, they use patterns such as "if ... in classical physics, it must be ... in quantum physics."

Conclusion 3: Students' mental models about the quantization of physical observables are context dependent.

Investigation of knowledge structures is a complex action, and so students' explanations about physics concepts were examined across contexts in this study. As Table VII presents, a change in the use of models is observed. That means students use different models in different contexts for the same phenomenon, and models vary based on the context. Sabella [70] explained that students' answers to questions might vary due to context. By using many contexts in this study, we identified that students' mental models about the quantization of physical observables are context dependent, as Bao [13], Bao and Redish [16], Hrepic [10,11], Hrepic, Zollman, and Rebello [12], Itza-Ortiz, Rebello, and Zollman [21], and Wittmann, Steinberg, and Redish [69] identified the context dependency of mental models in their work. The context dependency of mental models is meaningful because mental models are the minimum coherent structures used to explain phenomena. Therefore, if a scientific model is constructed and improved, and then used "robustly" across different contexts, then there might be a greater probability of "scientific understanding" in students' learning. However, if an unscientific model is constructed and used "robustly" across contexts along with wrong organizations, then unscientific conceptions might be more likely to occur in students' learning. Furthermore, if they are not modified, students might develop unscientific understandings about the phenomena. This is not the expected outcome of learning physics, because physics education aims to have students build the proper mental models for doing work in the discipline [8].

Conclusion 4: Students use a limited number of mental models across contexts.

Students displayed models in only 69 of the 279 instances studies in order to explain the quantization phenomenon. The frequency of model usage across contexts was almost $25 \%$. This ratio may explain students' difficulty in developing models about the quantization of physical observables, because mental models are coherent structures, and they require the organization of knowledge to have a single conceptual framework. Although the students used the SM to explain the quantization of physical observables 29 times in total, this is also limited when we consider that the study included 279 instances for 31 participants. The ratio for students' use of the SM across all contexts is almost $10 \%$ of all students. The small size of the ratio of students using the SM also indicates that students' understanding of the quantization of physical observables is limited.

Conclusion 5: Students hold scientific and unscientific fragments together in order to develop mental models.

Students' explanations reveal that they hold scientific and unscientific fragments together, and that they link these elements with each other in order to develop mental models. This result supports Norman's ([7], p. 8) finding that, "individuals' mental models might contain contradictory, erroneous, and unnecessary concepts." In this way, students developed hybrid unscientific models in addition to pure scientific or unscientific models in this study. The SM is a pure scientific model, and the IM and EM are pure unscientific models. However, the PSM, ShM, and AM are hybrid unscientific mental models that students hold about the quantization of physical observables, because hybrid models contain scientific and unscientific elements together. As a result, with the coherent combination [10-12,21] of these elements, a "new coherent structure"-a mental model-is developed, which is called a hybrid model. Hrepic, Zollman, and Rebello [12] explained that hybrid models are complex models since the construction of a hybrid model requires the use and organization of elements from different domains (in this study, scientific and unscientific domains) to construct knowledge.

In this study, we interpret the reason for hybrid unscientific models in terms of the explicit stress of "discreteness or (and) discreteness characteristic," as well as the implicit expression of "boundedness" in the textbooks and instruction about the construction of the PSM and ShM. This is because, in these models, students do not use boundedness for quantization appropriately. As a result, students incorporate "discreteness" with an inappropriate use of "boundedness" to develop these hybrid unscientific models.

Conclusion 6: Students may hold more than one mental model together. In other words, some students have mixed model states in which they hold different mental models about the phenomenon at the same time. They use their models inconsistently.

This result is compatible with Gentner's [5] study explaining that people can hold two or more "inconsistent" mental models together in the same domain. As Bao [13], Bao and Redish [16], Hrepic [10,11] and Hrepic, Zollman, and Rebello [12], Itza-Ortiz and Rebello [71], and ItzaOrtiz, Rebello, and Zollman [21] found, students had mixed model states about some physics phenomena. Some of the undergraduate second-year physics and physics education students in this study have mixed model states about quantization phenomenon. In other words, students hold different models about the phenomenon together in different contexts. This might be the result of each context having unique triggering elements that activate specific 
mental models. As Bao [13] explained, different physics questions might trigger different models.

Since the number of contexts in which we identified students' mental models was large, we were able to examine students' mental model states. These model states may vary in terms of closeness of the frameworks that allow understanding. This means, for example, that students can have a mixed state with the PSM and SM, which have more common concepts, or one student can have the ShM and $\mathrm{AM}$ at the same time about the quantization of energy. Furthermore, another student could have the SM and IM at the same time for the quantization of angular momentum. Because the SM and IM do not have common elements, they are completely different frameworks, no matter the closeness of the models with which students may hold them together. Chi [72] explained that students might use incorrect models inconsistently in order to make explanations or predictions for events. In this study, since students have mixed model states, they tend to use the models inconsistently across contexts. Physics and physics education students' inconsistent use of their models is compatible with the results of Bao's [13], Hrepic's [10], and Hrepic, Zollman, and Rebello's [12] findings. Again, this might be explained as a result of the contextual elements that activate students' models differently in different contexts describing the same phenomenon.

Conclusion 7: Students use fragments when they do not use models.

Construction of a mental model is a complex process. Students sometimes do not make explanations based on models, but rather based on fragments that are disperse or unorganized [34], unlinked or disconnected, or incoherently used [10]. In this study, students constructed their mental models by organizing memorized elements and fragments-especially facets. In the absence of some of these elements and links, students could not form a coherent framework, and so they tried to use these elements independently and ended up using them in an inconsistent way. Students also used memorized elements without stating their explanations. This type of physics knowledge is referred to as "nominal" and "not functional" [73]. These students, who have incoherent knowledge organization and confuse concepts are referred to as being in the transitional phase (Perret-Clerment, 1980, as cited in Chinn and Brewer [74]). Moreover, having fragmented knowledge forecloses the benefits of having coherent structure result from knowledge, such as remembering and inferring the details [73]. Because an examination of the nature of fragmented elements was outside our research aims, these were not explored further in this study.

Conclusion 8: Construction of the SM is based on "on the spot" and "previously thought or experienced" explanations, and students using the SM trust their knowledge more than other students. However, unscientific models are mainly constructed "on the spot" when the questions are asked.
In this study, we observed that while students who use the SM make explanations both on the spot and based on previous thought, the students who use the PSM, AM, ShM, IM, and EM present mostly on the spot explanations. In previous research, Vosniadou and Brewer [68] explained "on the spot" construction of mental models and Hrepic [11] identified that students constructed some mental models on the spot while answering questions about sound. Similarly, Corpuz and Rebello [14] identified that students' mental models of friction could be constructed "on the spot," but their macroscopic experiences influenced their mental models at the atomic level. These findings are surprising since "sound" and "friction" are everyday phenomena, but students constructed models on the spot. In this study, the students did not have any physical experience about the concepts from daily life. They might experience instances of quantization in the laboratory by conducting experiments, or they experience it through the course instruction by interpreting what is explained. For this reason, it is possible to construct all types of models on the spot. However, students construct the SMs based on mathematical elements of the quantization of angular momentum (in both the Bohr and quantum atoms). This result is also compatible with the studies of Itza-Ortiz and Rebello [71] and Itza-Ortiz, Rebello, and Zollman [21]. They identified that in order to explain physical situations in magnetic field contexts, students relied on equations more than before.

Norman [7] explained that individuals sometimes feel uncertain about their knowledge and that their mental models often contain some "degree of certainty" elements. By examining students' mental model characteristics in terms of their "assurance level," we found that those who used the SM were more certain than other students while making explanations. This might be because of their awareness of their own scientific knowledge, which leads them to trust the scientific knowledge they got from the instruction and textbooks.

Conclusion 9: Some models are more likely to be used than others.

In our examination of mental models used across contexts, we identified that many students use the SM and PSM. However, other models-ShM, AM, IM, and EM-are used by a small number of students. The common property of these local models is that they are unscientific. This pattern is important in order to understand students' knowledge organization about quantum theory. Other personal factors about the locality of unscientific models may explain this pattern.

Conclusion 10: A limited number of students (three) could transfer their mental models into a similar context.

St2 and St9, who used the SM and AM in their explanations of the quantization of angular momentum in the Bohr atom context, were able to transfer their models 
to explain the quantization of angular momentum in the quantum atom. In other words, they successfully used the same model in a similar context. Similarly, St7, who used the SM in her explanation of the quantization of energy in the Bohr atom context, was able to transfer her model to explain the quantization of energy in the quantum atom as well. This result is compatible with the findings of Itza-Ortiz, Rebello, and Zollman [21], which demonstrated that students could transfer their mental models from classical mechanics to electromagnetism concepts. The researchers explained that students do this when faced with abstract contexts. As these researchers explained, students' explanations are likely based on their experiences in the classroom. We already know that the quantum concepts researched in this study are abstract. Among the 27 students who used models, most of them did not transfer their models from the Bohr atom to the quantum atom to explain the quantization of energy and angular momentum.

\section{B. Implications}

The findings of this study indicate some points that modern physics instructors or teachers, students who are taking modern physics course, and modern physics textbook authors should consider.

(1) Links should be constructed between different physics concepts and contexts in the classes and textbooks. Some advance organizers such as concept maps and brief summaries should be used in order to foster students' linking of the concepts: In this study, we identified that students hold many incoherent unscientific ideas together with their unscientific mental models. Incorrect ideas must be corrected [24] for students to attain scientific knowledge. In addition to their unscientific conceptions, students sometimes had correct ideas, but they often used these inconsistently. Being a good physicist requires having organized knowledge, which permits remembering and inferring details [73], so links among concepts should be constructed alongside their explanation. This might be possible through the repetition of previous concepts in order to connect new learning with previously learned concepts. In addition, important concepts might be stressed and the construction of links among the concepts might be fostered by using concept maps. That means concept mapping should be used in the classes and textbooks to facilitate links among concepts. In addition, summaries at the end of the classes and textbook chapters might be used to keep the concepts fresh and might facilitate students to make easier connections with the concepts in subsequent sections and chapters. Physics concepts are not isolated, but in fact constitute the elements of a coherent framework, so "meaning" should be constructed by coherently linking different concepts. These strategies might help students better organize their knowledge.

(2) Students should force themselves to develop mental models: With the use and stress to links in the classes and textbooks, students should link the concepts in coherent ways for better understanding, and they should push themselves to organize their knowledge, because having mental models about course concepts fosters the development of complex organized knowledge about the phenomena. It also allows for an easier retrieval process.

(3) The instructor's knowledge should allow them to predict students' probable knowledge structures: The instructor's knowledge about the quantization of physical observables is important in shaping instruction. Having complex scientific knowledge consisting of advanced-level concepts may allow the instructor to predict how students will approach concepts and how they will organize their knowledge. In this way, instructors might predict students' inappropriate use of some concepts and their construction of unscientific models. Then they can consider some precautions to prevent students from organizing their knowledge incorrectly, manipulate their unscientific models, and recover them by manipulating the instruction.

(4) The instructor should identify students' prior knowledge: In their instruction, educators should expect their students to have diverse types of ideas [24], whether organized or unorganized. Students' knowledge structures should be identified because having a background in either classical and quantum concepts is important for coherent knowledge organization. Advance organizers such as concept maps might be used at the beginning of the instruction in the exploration of students' prior knowledge [75]. Moreover, students should be helped to use their knowledge elements correctly in their classes. As this study indicates, background knowledge of students' mental models is highly important and the SMs should be emphasized persistently over a long period of time. This allows for students to use their models in subsequent courses about quantum theory.

\section{ACKNOWLEDGMENTS}

We would like to present special thanks to Professor Dr. Edward Frederick (Joe) Redish. We also thank Associate Professor Dr. Ömer Faruk Özdemir, Associate Professor Dr. Esen Uzuntiryaki, Bülent Ecevit University, Middle East Technical University, and the Scientific and Technological Research Council of Turkey. 


\section{APPENDIX A: THE CODES FOR INVESTIGATION OF KNOWLEDGE ORGANIZATIONS}

Appendix A presents the mutually exclusive codes given in Fig. 2 and Table V. Mental models displayed by students indicate coherently use these elements in different compositions.

\begin{tabular}{|c|c|c|c|}
\hline No & Code & Abbr. & Definition of the code \\
\hline 1 & Only bound particle & OBP & $\begin{array}{l}\text { Specificity of the quantization of physical observables for only the particle confined } \\
\text { in a region. }\end{array}$ \\
\hline 2 & $\begin{array}{l}\text { Discreteness }^{(1)} \text { or }(\text { and }) \\
\text { Discreteness characteristic } \\
(2)\end{array}$ & $\mathrm{D} / \mathrm{DC}$ & $\begin{array}{l}{ }^{(1)} \text { For the physical observables such as energy, angular momentum, having only } \\
\text { discrete values. }{ }^{(2)} \text { Restriction of the values of the physical observables, and so } \\
\text { having only certain (allowed) values. }\end{array}$ \\
\hline 3 & Natural characteristic & $\mathrm{NC}$ & $\begin{array}{l}\text { Specificity of the quantization of physical observables for the nature of atomic } \\
\text { systems. }\end{array}$ \\
\hline 4 & Any values & $\mathrm{AV}$ & No restriction of the values of the physical observables, and having any values. \\
\hline 5 & Artificial characteristic & $\mathrm{AC}$ & External manipulation of the values of the physical observables. \\
\hline 6 & Einstein’s relativity & ER & $\begin{array}{l}\text { Considering the quantization of physical observables as a phenomenon of } \\
\text { Einstein's theory of relativity. }\end{array}$ \\
\hline 7 & Change & $\mathrm{C}$ & Considering the quantization of physical observables as any kind of change. \\
\hline 8 & Integration & I & $\begin{array}{l}\text { Considering the quantization of physical observables as an integration process to } \\
\text { make the values of the physical observables continuous. }\end{array}$ \\
\hline 9 & Every particle & EP & $\begin{array}{l}\text { Considering the quantization of physical observables is observed for every atomic } \\
\text { particle. }\end{array}$ \\
\hline
\end{tabular}

\section{APPENDIX B: A SAMPLE CODING}

Appendix B presents the codes (with abbreviations) identified in a student' explanations. Since the original text was in Turkish, the English translation of the text was also presented with the codes in order to show the coding. In the data, each minimum meaningful chunk of a sentence, figure, or formula indicating quantization was coded with a different code. The sample text contains three different codes that are OBP, D/DC, NC.

\begin{tabular}{|c|c|}
\hline $\begin{array}{l}\text { Excerpt } \\
\text { Information }\end{array}$ & Excerpts \\
\hline${ }^{a}$ in Turkish & $\begin{array}{l}\text { St15: Evet var. Bu şey gibi... I11... (Emisyon spektrumunu göstererek) Atomdaki elektron } \\
\text { üst yörüngeden alt yörüngeye geçip orbitini değiştirince atom foton yayıor. Bunlar } \\
\text { (spektrum çizgilerini göstererek) foton. Enerji sürekli değil, belli bi miktar enerji. } \\
\text { Mesela, elektronun üçüncü yörüngeden ikinci yörüngeye geçişiyle foton elektronun bu } \\
\text { enerji seviyelerinde sahip olduğu enerjiler arasındaki fark kadar enerji alabilir. O } \\
\text { yüzden bu çizgiler oluşur. }\end{array}$ \\
\hline in English & $\begin{array}{l}\text { St15: Yes, I have. This is like... Umm... (By showing the emission spectrum) An atom } \\
\text { emits a photon when an atomic electron changes its orbit while jumping from upper } \\
\text { orbit to lower orbit. These are (by showing the spectral lines) the photons. The energy is } \\
\text { not continuous; a certain amount of energy. For example, in the electron's movement } \\
\text { from the third orbit to the second orbit, a photon can take the amount of energy between } \\
\text { these energy levels that the electron has. Therefore, these lines occur. }\end{array}$ \\
\hline
\end{tabular}

${ }^{\mathrm{a} O r i g i n a l ~ d a t a}$ and coding are in Turkish.

\section{APPENDIX C: FREQUENCY AND PERCENTAGE OF EACH CODE IDENTIFIED IN STUDENTS' EXPLANATIONS ABOUT QUANTIZATION}

Appendix C presents the frequency and percentage of each code. This output was created by a qualitative data analysis program used in the research. In this research, students mostly explained the quantization phenomena by focusing "discreteness". 


\begin{tabular}{lrr}
\hline \hline Codes & $\mathrm{f}$ & $(\%)$ \\
\hline MENTAL MODELS OF QUANTIZATION & & \\
1 ONLY BOUND PARTICLE OBP & 125 & 6.16 \\
2 DISCRETENESS or (and) DISCRETENESS CHARACTERISTIC D-DC & 1191 & 58.69 \\
3 NATURAL CHARACTERISTIC NC & 275 & 13.55 \\
4 ANY VALUES AV & 53 & 2.61 \\
5 ARTIFICIAL CHARACTERISTIC AC & 61 & 3.00 \\
6 EINSTEIN'S RELATIVITY ER & 26 & 1.28 \\
7 CHANGE C & 112 & 5.52 \\
8 INTEGRATION I & 53 & 2.61 \\
9 EVERY PARTICLE EP & 133 & 6.55 \\
\hline \hline
\end{tabular}

[1] I. M. Greca and M. A. Moreira, Mental, physical and mathematical models in the teaching and learning of physics, Sci. Educ. 86, 106 (2002).

[2] K. J. W. Craik, The Nature of Explanation (Cambridge University Press, Cambridge, England, 1943).

[3] P. N. Johnson-Laird, Mental Models (Cambridge University Press, Cambridge, England, 1983).

[4] D. Gentner and A. L. Stevens, Mental Models (Lawrence Erlbaum Associates, Hillsdale, NJ, 1983).

[5] D. Gentner, Mental models, psychology of, in International Encyclopedia of the Social, and Behavioral Sciences, edited by N. J. Smelser and P. B. Bates (Elsevier Science, Amsterdam, Netherlands, 2002), pp. 9683-9687.

[6] D. Gentner and E. W. Whitley, Mental models of population growth: A preliminary investigation, in Environment, Ethics, and Behavior: The Psychology of Environmental Valuation and Degradation, edited by A. M. Bazerman, D. M. Messick, E. Tenbrunsel, and K. Wade-Benzoni (New Lexington Press, San Francisco, CA, 1997), pp. 209-233.

[7] D. Norman, Some observations on mental models, in Mental Models, edited by D. Gentner and A. Stevens (Lawrence Erlbaum Associates, Hillsdale, NJ, 1983), pp. 7-14.

[8] E. F. Redish, Implications of cognitive studies for teaching physics, Am. J. Phys. 62, 796 (1994).

[9] A. A. diSessa, Why "conceptual ecology" is a good idea, in Reconsidering Conceptual Change: Issues in Theory, and Practice, edited by M. Limon and L. Mason (Kluwer Academics Publishers, Dordrecht, Netherlands, 2002), pp. 29-60.

[10] Z. Hrepic, Identifying students' mental models of sound propagation, Master's thesis, Kansas State University, 2002.

[11] Z. Hrepic, Development of a real time assessment of students' mental models of sound propagation, Ph.D thesis, Kansas State University, 2004.

[12] Z. Hrepic, D. A. Zollman, and N. S. Rebello, Identifying students' mental models of sound propagation: The role of conceptual blending in understanding conceptual change, Phys. Rev. ST Phys. Educ. Res. 6, 020114 (2010).
[13] L. Bao, Dynamics of student modeling: A theory, algorithms and application to quantum mechanics, Ph.D thesis, University of Maryland, 1999.

[14] E. G. Corpuz and N. S. Rebello, Introductory college physics students' mental models of friction and related phenomena at the microscopic level, in Proceedings of Annual Meeting of the National Association for Research in Science Teaching, 2005, Dallas, TX.

[15] E. D. Corpuz and N.S. Rebello, Investigating students' mental models and knowledge construction of microscopic friction: Implications for curriculum design and development-Part I, Phys. Rev. ST Phys. Educ. Res. 7, 020102 (2011).

[16] L. Bao and E. F. Redish, Model analysis: Representing and assessing the dynamics of student learning, Phys. Rev. ST Phys. Educ. Res. 2, 010103 (2006).

[17] K.S. Taber, Conceptual resources for learning science: Issues of transience and grain-size in cognition and cognitive structure, Int. J. Sci. Educ. 30, 1027 (2008).

[18] M. C. Wittmann, R. N. Steinberg, and E. F. Redish, Making sense of how students make sense of mechanical waves, Phys. Teach. 37, 15 (1999).

[19] A. Borges and J. K. Gilbert, Mental models of electricity, Int. J. Sci. Educ. 21, 95 (1999).

[20] Z. Hrepic, D. Zollman, and S. Rebello, Eliciting and Representing Hybrid Mental Models, in Proceedings of Annual Meeting of the National Association for Research in Science Teaching, 2005, Dallas, TX.

[21] S. F. Itza-Ortiz, S. Rebello, and D. Zollman, Students' models of Newton's second law in mechanics and electromagnetism, Eur. J. Phys. 25, 81 (2004).

[22] D. Hestenes, M. Wells, and G. Swackhamer, Force Concept Inventory, Phys. Teach. 30, 141 (1992).

[23] E. G. Corpuz, Students' modeling of friction at the microscopic level, Ph.D thesis, Kansas State University, 2006.

[24] R. Scherr, Modeling student thinking: An example from special relativity, Am. J. Phys. 75, 272 (2007).

[25] P. Hubber, Year 12 students' mental models of the nature of light, Res. Sci. Educ. 36, 419 (2006). 
[26] R. Vadnere and P. Joshi, On analysis of the perceptions of standard 12 students regarding a physics concept using techniques of quantum mechanics, Phys. Educ. J. 26, 279 (2009).http://physics.unipune.ac.in/ phyed/26.4/26.4\% 20Rajendra\%20Vadnere.pdf

[27] G. Chiou and O. R. Anderson, A study of undergraduate physics students' understanding of heat conduction based on mental model theory and an ontology-process analysis, Sci. Educ. 94, 825 (2010).

[28] H. R. Sadaghiani, Conceptual and mathematical barriers to students learning quantum mechanics, Ph.D thesis, The Ohio State University, 2005.

[29] P. Wattanakasiwich, Model of understanding of probability in modern physics, Ph.D thesis, Oregon State University, 2005.

[30] M. Budde, H. Niedderer, P. Scott, and J. Leach, Electronium: A quantum atomic teaching model, Phys. Educ. 37, 197 (2002).

[31] M. Budde, H. Niedderer, P. Scott, and J. Leach, The quantum atomic model 'Electronium': A successful teaching tool, Phys. Educ. 37, 204 (2002).

[32] E. Çataloğlu, Development and validation of an achievement test in introductory quantum mechanics: The quantum mechanics visualization instrument (QMVI), Ph.D thesis, Pennsylvania State University, 2002.

[33] N. Didiş, A. Eryılmaz, and Ş. Erkoç, Pre-service physics teachers' comprehension of quantum mechanical concepts, Eurasia J. Math. Sci. \& Tech. Educ. 6, 227 (2010). http:// www.ejmste.com/v6n4/eurasia_v6n4_didis.pdf

[34] D. E. Gardner, Learning in quantum mechanics, Ph.D thesis, Purdue University, 2002.

[35] G. Ireson, The quantum understanding of pre-university physics students, Phys. Educ. 35, 15 (2000).

[36] J. L. Ke, M. Monk, and R. Duschl, Learning introductory quantum physics: Sensori-motor experiences and mental models, Int. J. Sci. Educ. 27, 1571 (2005).

[37] R. Müller and H. Wiesner, Students' conceptions of quantum physics, in Proceedings of Annual Meeting of the National Association for Research in Science Teaching, 1999, Boston, MA.

[38] R. Müller and H. Wiesner, Teaching quantum mechanics on an introductory level, Am. J. Phys. 70, 200 (2002).

[39] R. V. Olsen, Introducing quantum mechanics in the upper secondary school: A study in Norway, Int. J. Sci. Educ. 24, 565 (2002).

[40] Ö. Özcan, N. Didiş, and M. F. Taşar, Students' conceptual difficulties in quantum mechanics: Potential well problems, Hacettepe Un. J. Educ. 36, 169 (2009). http://www .efdergi.hacettepe.edu.tr/200936\%C3\%96ZG\%C3\%9CR $\% 20 \%$ C $3 \% 96 Z$ CAN.pdf

[41] C. Singh, Student understanding of quantum mechanics, Am. J. Phys. 69, 885 (2001).

[42] C. Singh, M. Belloni, and W. Christian, Improving students' understanding of quantum mechanics, Phys. Today 59, 43 (2006).

[43] D. F. Styer, Common misconceptions regarding quantum mechanics, Am. J. Phys. 64, 31 (1996).

[44] G. Pospiech, Uncertainty and complementarity: The heart of quantum physics, Phys. Educ. 35, 393 (2000).
[45] A. T. Sauer, The effect of mathematical model development on the instruction of the acceleration to introductory physics students, Ph.D thesis, University of Minnesota, 2000.

[46] J. Strnad, Quantum physics for beginners, Phys. Educ. 16, 88 (1981).

[47] E. Çataloğlu and R. W. Robinett, Testing the development of student conceptual and visualization understanding in quantum mechanics through the undergraduate career, Am. J. Phys. 70, 238 (2002).

[48] A. Mashhadi and B. Woolnough, Insights into students' understanding of quantum physics: Visualizing quantum entities, Eur. J. Phys. 20, 511 (1999).

[49] K. Mannila, I. Koponen, and J. A. Niskanen, Building a picture of students' conceptions of wave- and particle-like properties of quantum entities, Eur. J. Phys. 23, 45 (2002).

[50] A. Cuppari, G. Rinaudo, O. Robutti, and P. Violino, Gradual introduction of some aspects of quantum mechanics in a high school curriculum, Phys. Educ. 32, 302 (1997).

[51] K. Dobson, I. Lawrence, and P. Britton, The A to B of quantum physics, Phys. Educ. 35, 400 (2000).

[52] L. T. Escalada, Investigating the applicability of activitybased quantum mechanics in a few high school physics classrooms, Ph.D thesis, Kansas State University, 1997.

[53] C. Frederick, A mechanical model for teaching quantum mechanics, Am. J. Phys. 46, 242 (1978).

[54] P. Hadzidaki, G. Kalkanis, and D. Stavrou, Quantum mechanics: A systemic component of the modern physics paradigm, Phys. Educ. 35, 386 (2000).

[55] G. Kalkanis, P. Hadzidaki, and D. Stavrou, An instructional model for a radical conceptual change towards quantum mechanics concepts, Sci. Educ. 87, 257 (2003).

[56] P. G. Kwiat and L. Hardy, The mystery of the quantum cakes, Am. J. Phys. 68, 33 (2000).

[57] M. Michelini, R. Ragazzon, L. Santi, and A. Stefanel, Proposal for quantum physics in secondary school, Phys. Educ. 35, 406 (2000).

[58] Y. Shadmi, Teaching the exclusion principle with philosophical flavor, Am. J. Phys. 46, 844 (1978).

[59] G. Vandegrift, The maze of quantum mechanics, Eur. J. Phys. 23, 513 (2002).

[60] M. C. Wittmann, Making sense of how students come to an understanding of physics: An example from mechanical waves, Ph.D thesis, University of Maryland, 1998.

[61] Department of Physics. Course list. 2010, Available at http://www.physics.metu.edu.tr/courses/courses.html? $\mathrm{q}=\mathrm{P} 2 \# \mathrm{C} 2300202$.

[62] R. C. Bogdan and S. K. Biklen, Qualitative Research for Education: An Introduction to Theory and Methods (Allyn and Bacon, Boston, MA, 1992).

[63] M. B. Miles and A. M. Huberman, Qualitative Data Analysis (Sage Publications, Newbury Park, CA, 1984).

[64] M. D. LeCompte and J. P. Goetz, Problems of reliability and validity in ethnographic research, Rev. Educ. Res. 52, 31 (1982).

[65] A. Yıldırım and H. Şimşek, Nitel Araştırma Yöntemleri (Seçkin, Ankara, 2005).

[66] J. A. Maxwell, Qualitative Research Design: An Interpretive Approach (Sage Publications Thousand Oaks, CA, 1996). 
[67] J. R. Fraenkel and N. E. Wallen, How to Design \& Evaluate Research in Education (McGraw Hill, Boston, MA, 2000).

[68] S. Vosniadou and W. F. Brewer, Mental models of the earth: A study of conceptual change in childhood, Cogn. Psychol. 24, 535 (1992).

[69] M. C. Wittmann, R. N. Steinberg, and E. F. Redish, Understanding and affecting student reasoning about sound waves, Int. J. Sci. Educ. 25, 991 (2003).

[70] M. S. Sabella, Using the context of physics problem solving to evaluate the coherence of student knowledge, Ph.D thesis, University of Maryland, 1999.

[71] S. F. Itza-Ortiz and S. N. Rebello, A Summary of students' mental models and their applications in contexts pertaining to Newton's II law, in Proceedings of the meeting of the Physics Education Research Conference, 2002, Boise, ID.
[72] M. T. H. Chi, Three types of conceptual change: Belief revision, mental model transformation, and categorical shift, in Handbook of Research on Conceptual Change, edited by S. Vosniadou (Erlbaum, Hillsdale, NJ, 2008), pp. 61-82.

[73] F. Reif, Millikan Lecture 1994: Understanding and teaching important scientific thought processes, Am. J. Phys. 63, 17 (1995).

[74] C. A. Chinn and W. F. Brewer, The theories of knowledge acquisition, in Handbook of Science Education, edited by B. J. Fraser and K. G. Tobin (Kluwer Academics Publishers, Great Britain, 1998), pp. 97-113.

[75] M. Willerman and R. A. MacHarg, The concept map as an advance organizer, J. Res. Sci. Teach. 28, 705 (1991). 